\title{
The network of non-coding RNAs and their molecular targets in breast cancer
}

\author{
Francesca Crudele ${ }^{1,2}$, Nicoletta Bianchi ${ }^{3}$, Eva Realii , Marco Galasso ${ }^{1}$, Chiara Agnoletto ${ }^{5}$ and Stefano Volinia ${ }^{1,2^{*}}$
}

\begin{abstract}
Background: Non-coding RNAs are now recognized as fundamental components of the cellular processes. Noncoding RNAs are composed of different classes, including microRNAs (miRNAs) and long non-coding RNAs (IncRNAs). Their detailed roles in breast cancer are still under scrutiny.

Main body: We systematically reviewed from recent literature the many functional and physical interactions of noncoding RNAs in breast cancer. We used a data driven approach to establish the network of direct, and indirect, interactions. Human curation was essential to de-convolute and critically assess the experimental approaches in the reviewed articles. To enrol the scientific papers in our article cohort, due to the short time span (shorter than 5 years) we considered the journal impact factor rather than the citation number.

The outcome of our work is the formal establishment of different sub-networks composed by non-coding RNAs and coding genes with validated relations in human breast cancer. This review describes in a concise and unbiased fashion the core of our current knowledge on the role of IncRNAs, miRNAs and other non-coding RNAs in breast cancer.

Conclusions: A number of coding/non-coding gene interactions have been investigated in breast cancer during recent years and their full extent is still being established. Here, we have unveiled some of the most important networks embracing those interactions, and described their involvement in cancer development and in its malignant progression.
\end{abstract}

\section{Background}

The non-coding RNAs are a still growing and heterogeneous set of genes that act upon other non-coding, or coding, RNAs and ultimately regulate most biological processes in the human cell. They have been extensively studied, mainly after year 2000, in human malignancies and particularly in the cancers of the mammary gland.

The studies on non-coding RNAs and breast cancer (BC) prevalently investigate one or few RNAs that have been selected from clinical genomics. Typically, such works analyze the $\mathrm{BC}$ transcriptomes from retrospective cohort studies.

\footnotetext{
* Correspondence: vinsfn@unife.it

'Department of Morphology, Surgery and Experimental Medicine, University of Ferrara, Ferrara, Italy

${ }^{2}$ LTTA, University of Ferrara, Ferrara, Italy

Full list of author information is available at the end of the article
}

We decided to apply a data-driven study selection rather than use only our human and scientific sensitivity. Firstly, we performed two queries to isolate from PubMed all the articles on ncRNAs and miRNAs published in the last 5 years on $\mathrm{BC}$ (Table 1). To triage the studies considered for this review we then selected the journals based on their impact factors. A different, and probably fairer, criterion would have been the citation number, but this is impractical for articles with recent publication time, such as those we wanted to consider here. Furthermore, we let the skeleton of our work to self-assemble using the data themselves. We explored this procedure in our earlier organized view of the role of non-coding RNAs in drug resistance. Using an approach where the nodes are the non-coding RNAs, or their target genes and the edges (connections) are the PMIDs of their relative articles, we obtained a network that was used to organize this review. Separate groups of 
RNAs and genes that were not linked will be discussed as separate entities or 'sub-networks'. A statistical analysis of the network helped to identify nodes (RNAs or genes) with particular properties (i.e. degree, or number of interacting RNA/genes) and ultimately for prioritization. The number of citation of an RNA/gene depends both on its 'real' importance as determined by the experimental method, or on its 'perceived' importance, making it an element of choice by the investigators. The network of non-coding RNAs (ncRNAs) and their targets in $\mathrm{BC}$, defined using this approach is shown in Fig. 1. The graph shows the non-coding RNAs, and their targets, validated in at least two independent sources from literature. The edges are directed (i.e. from the non-coding RNA to its target). In red are depicted the links indicating a repressive action (flat arrowhead), while in black are those showing activation (with traditional arrowhead). Dashed lines correspond to edges indicating indirect effects. The network in Fig. 1 is the essential core showing what remains after filtering the nodes (non-coding RNAs) based on their degrees (i.e. the number of connections to targets). Detailed information about the network composition are reported in Table 2. The filtered out nodes, basically un-replicated findings, are shown in Table 3. They are still worthy of consideration, but were strictly left out of the major network.

We will discuss here the most prominent subnetworks and their single components and interactions, with the goal of understanding the involvement and roles of non-coding RNAs in BC.

\section{The miR-200/205 ZEB2 sub-network}

Figure 2 shows that ZEB2 is a pivotal actor in this subnetwork, interconnecting the cluster composed by miR-

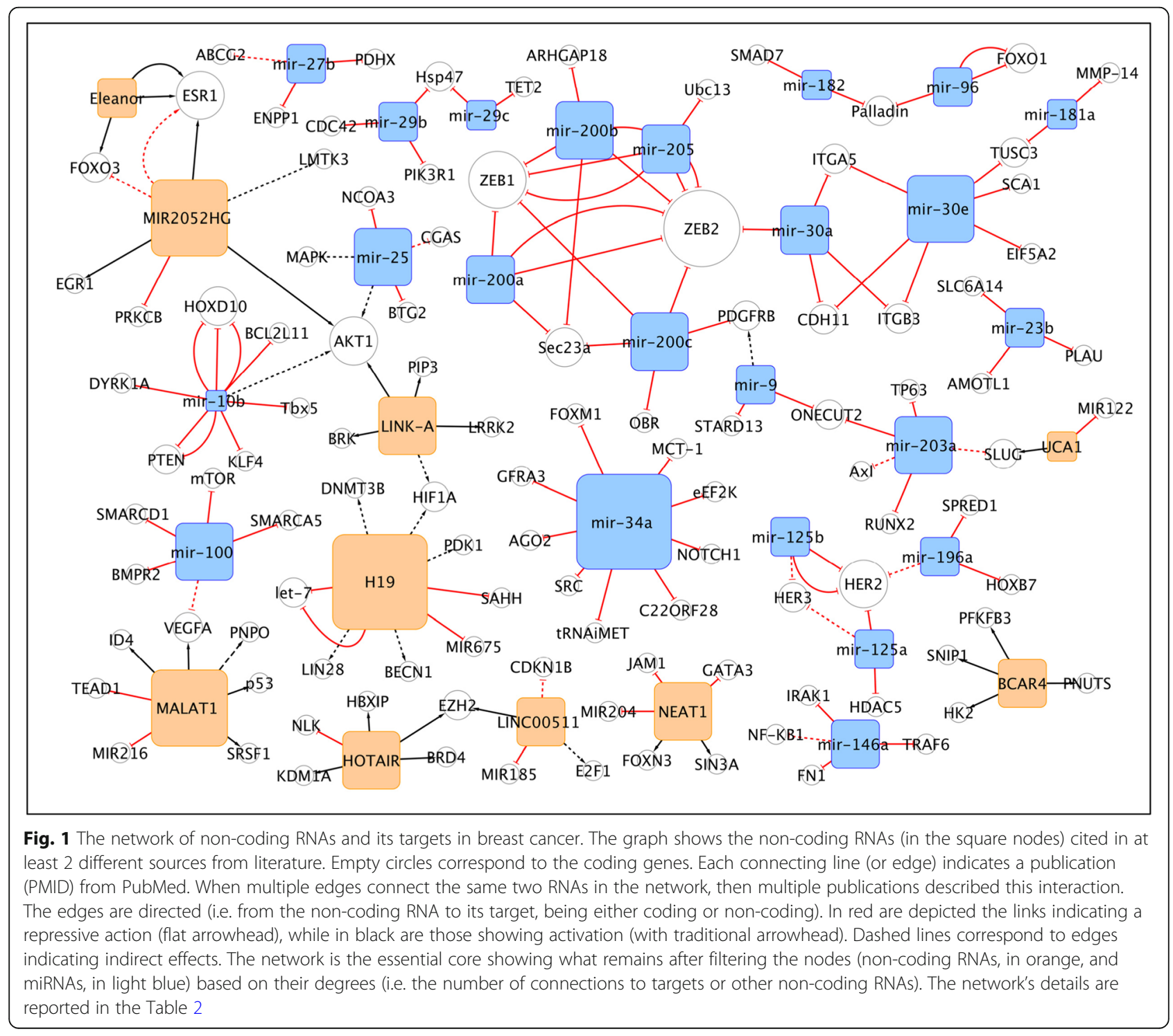


Table 1 Queries with keywords used for the selection of articles from PubMed

\begin{tabular}{|c|c|}
\hline Query & $\begin{array}{l}\text { Items } \\
\text { found }\end{array}$ \\
\hline $\begin{array}{l}\text { "Search ((((microRNA OR miRNA OR ncRNA OR "'"non coding RNA"'" OR IncRNA) AND "'"last } 5 \text { years"'"[PDat]) AND ("'breast } \\
\text { neoplasms"'"[MeSH Terms] OR "'breast carcinoma"' OR "'breast cancer"')) AND "'llast } 5 \text { years"'"[PDat]) Sort by: [pubsolr12]" }\end{array}$ & 5219 \\
\hline $\begin{array}{l}\text { "Search (ncRNA OR "'"noncodingRNA"'" OR "'"non coding RNA"'" OR IncRNA) AND "'"last } 5 \text { years"'"[PDat]) AND ("'breast neoplasms"'"[MeSH } \\
\text { Terms] OR "'breast carcinoma"'" OR "'"breast cancer"')) AND "'last } 5 \text { years"'[PDat]) Sort by: [pubsolr12]" }\end{array}$ & 4234 \\
\hline
\end{tabular}

200a/b/c and miR-205 with that of miR-30a/e and miR181. Several research groups independently asserted that $\mathrm{miR}-200 \mathrm{a} / \mathrm{b} / \mathrm{c}$ are down-regulated in triple negative breast cancer (TNBC) and function as metastasis suppressor reducing epithelial mesenchymal transition (EMT), tumour invasion and drug resistance [142]. MiR-200 family's components target other genes that antagonize malignant processes, among them Rho GTPase-activating protein 18 (ARHGAP18), an important regulator of cell shape, spreading, migration, and angiogenesis [143] and the leptin receptor (OBR), which promotes the formation of cancer stem-like cells (CSCs) and up-regulates the obesityassociated adipokine itself associated to BC [144]. Furthermore, in this subnetwork miR-205 is involved in the modulation of basal-like $\mathrm{BC}$ motility mediated by the $\triangle \mathrm{Np} 63 \alpha$ pathway, by preserving the epithelial cells characters [145]. Mir-205 also is negatively correlated with DNA damage repair, promoting radio-sensitivity in TNBC, by targeting the ubiquitin conjugating enzyme E2N (UBC13) [146]. In contrast, Le et al. demonstrated that delivery of miR-200 family (miR-200a/b/c) by extracellular vesicles, through the circulatory system from highly metastatic tumour cells to poorly metastatic cells, in which ZEB2 and SEC23A were down-regulated, induced EMT and conferred the ability to colonize distant tissues [147]. Further considerations on opposite effects of ncRNAs could be drawn by the second cluster, where the miR-30's family members suppressed cell invasion in vitro and bone metastasis in vivo by targeting genes implicated in invasiveness (ITGA5, ITGB3) and osteo-mimicry (CDH11) in TNBC [148]. Consistently, miR-30a was involved in EMT regulation, upon TP53 stimulation, by targeting ZEB2 [149], while miR-30e displayed an onco-suppressor role through the modulation of ataxin 1 (SCA1) and EIF5A2, two disruptors of the $\mathrm{BC}$ acini morphogenesis promoted by laminin111 (LN1) [100]. MiR-181a could also lead to a reduction in the activation of pro-MMP-2, cell migration and invasion of $\mathrm{BC}$ cells through matrix-metalloproteinase MMP-14 [150]. In an apparently opposed fashion, Kuancan et al. demonstrated that miR-181a and miR-30e, once stimulated by SOX2 activation, could promote migration and metastasis dissemination in Basal and Luminal $\mathrm{BC}$ via silencing of Tumour Suppressor Candidate 3 (TUSC3) [151]. This subnetwork includes another crucial connection between miR-200c and miR-9, as antagonistic modulators of PDGFR $\beta$-mediated vasculogenesis in TNBC.
High levels of miR-9 exerted pro-metastatic function and mediated the acquisition of a mesenchymal and aggressive phenotype. In addition, miR-9 enhanced the generation of vascular lacunae both in vitro and in vivo, in part by direct repression of STARD13, and was also required for PDGFRßmediated activity. On the other hand, miR-200c in TNBC models strongly inhibited tumour growth and impaired tumour cell-mediated vascularization, by inhibiting PDGFRß activity in vascular lacunae and acting on ZEB1, one of the main transcriptional factors in EMT induction [152]. Furthermore, miR-9 in collaboration with miR-203a could lead to a CSC phenotype and to drug resistance after their release from exosomal vesicles (EV), upon treatment with chemotherapeutic agents. These miRNAs target the transcription factor One Cut Homeobox 2 (ONECUT2), whose reduction induces the expression of a variety of stemness-associated genes, including NOTCH1, SOX9, NANOG, OCT4, and SOX2 [83]. Blocking the EV miRNA-ONECUT2 axis could constitute a potential strategy to maximize the anticancer effects of chemotherapy, as well as to reduce chemoresistance. MiR-203a can collaborate with miR-135 (not showed in this subnetwork) to inhibit cell growth, migration and invasion, by the down-regulation of Runx 2 and IL11, MMP-13 and PTHrP targets. Indeed, an aberrant expression of Runx2, which promotes tumour growth and bone metastasis formation, was detected in $\mathrm{BC}$ [67]. This subnetwork highlights another connection of miR-203a, occurring with the long non coding UCA1 which affects directly and indirectly the snail family transcriptional repressor 2 (SLUG). MiR-203 prevents the induction of motility in luminal $\mathrm{BC}$ cells, through downregulation of $\triangle \mathrm{Np} 63 \alpha$ activity, and the inhibition of its SLUG and AXL targets [145]. Of interest, UCA1 expression in BC cells correlated with TGF- $\beta$-induced EMT and tumour metastasis. Mechanistically UCA 1 is up-regulated by TGF- $\beta$ and cooperates with the LINC02599 (AC026904.1) in order to promote SLUG activation and maintenance [1]. Furthermore, UCA1 was proposed to act as a competing endogenous RNA (ceRNA) to sequester miR122 , thus promoting $B C$ invasion. Interestingly, a mechanism mediated by insulin-like growth factor 2 messenger RNA binding protein (IMP1) and repressing invasion has also been hypothesized, via UCA1 decay through the recruitment of the CCR4-NOT1 deadenylase complex. According to this model, IMP1 could compete with UCA1 for binding to miR-122 and restore miRNA targets to inhibit cell invasion [153]. 
Table $\mathbf{2}$ List of ncRNA-target and the type of interaction present in the network

\begin{tabular}{|c|c|c|c|c|c|c|c|}
\hline & \\
\hline ncRNA & Direct target & Direct effect* & PMID & ncRNA & Direct target & Direct effect* & PMID \\
\hline$\overline{B C A R 4}$ & HK2 & pos & 28963395 & mir-200c & OBR & neg & 25840984 \\
\hline BCAR4 & PFKFB3 & pos & 28963395 & mir-200c & ZEB1 & neg & 27402080 \\
\hline BCAR4 & PNUTS & pos & 25416949 & mir-200c & $\operatorname{Sec} 23 a$ & neg & 25401471 \\
\hline BCAR4 & SNIP1 & pos & 25416949 & mir-200c & ZEB2 & neg & 25401471 \\
\hline Eleanor & ESR1 & pos & 25923108 & mir-200c & PDGFRB & neg & 27402080 \\
\hline Eleanor & ESR1 & pos & 31439835 & mir-203a & $A \times l$ & neg & 26292363 \\
\hline Eleanor & FOXO3 & pos & 31439835 & mir-203a & ONECUT2 & neg & 31118200 \\
\hline H19 & DNMT3B & pos & 31340867 & mir-203a & RUNX2 & neg & 25634212 \\
\hline H19 & HIF1A & pos & 29106390 & mir-203a & SLUG & neg & 26292363 \\
\hline H19 & let-7 & neg & 28102845 & mir-203a & TP63 & neg & 26292363 \\
\hline H19 & let-7 & neg & 29106390 & mir-205 & Ubc13 & neg & 25476932 \\
\hline H19 & LIN28 & pos & 28102845 & mir-205 & ZEB1 & neg & 25476932 \\
\hline H19 & MIR675 & neg & 30803129 & mir-205 & ZEB1 & neg & 26292362 \\
\hline H19 & PDK1 & pos & 29106390 & mir-205 & ZEB2 & neg & 26292362 \\
\hline H19 & $\mathrm{SAHH}$ & neg & 31340867 & MIR2052HG & EGR1 & pos & 30944027 \\
\hline H19 & BECN1 & pos & 31340867 & MIR2052HG & ESR1 & pos & 27758888 \\
\hline HOTAIR & BRD4 & pos & 28846832 & MIR2052HG & PRKCB & neg & 30944027 \\
\hline HOTAIR & $\mathrm{EZH} 2$ & pos & 30764859 & MIR2052HG & AKT1 & pos & 27758888 \\
\hline HOTAIR & HBXIP & pos & 26719542 & MIR2052HG & FOXO3 & neg & 27758888 \\
\hline HOTAIR & KDM1A & pos & 26719542 & MIR2052HG & ESR1 & pos & 30944027 \\
\hline HOTAIR & NLK & neg & 30764859 & MIR2052HG & LMTK3 & pos & 30944027 \\
\hline LINC00511 & $\mathrm{EZH} 2$ & pos & 31395854 & mir-23b & AMOTL1 & neg & 26178901 \\
\hline LINC00511 & MIR185 & neg & 30482236 & mir-23b & PLAU & neg & 26178901 \\
\hline LINC00511 & CDKN1B & neg & 31395854 & mir-23b & SLC6A14 & neg & 31269432 \\
\hline LINC00511 & E2F1 & pos & 30482236 & mir-25 & BTG2 & neg & 29310680 \\
\hline LINK-A & AKT1 & pos & 28218907 & mir-25 & NCOA3 & neg & 28920955 \\
\hline LINK-A & BRK & pos & 26751287 & mir-25 & AKT1 & pos & 29310680 \\
\hline LINK-A & LRRK2 & pos & 26751287 & mir-25 & MAPK & pos & 29310680 \\
\hline LINK-A & HIF1A & pos & 26751287 & mir-25 & CGAS & neg & 28920955 \\
\hline LINK-A & PIP3 & pos & 28218907 & mir-27b & ENPP1 & neg & 26065921 \\
\hline MALAT1 & ID4 & pos & 28652379 & mir-27b & PDHX & neg & 30012170 \\
\hline MALAT1 & MIR216 & neg & 30982780 & mir-27b & ABCG2 & neg & 26065921 \\
\hline MALAT1 & p53 & pos & 28652379 & mir-29b & $\mathrm{CDC} 42$ & neg & 25622979 \\
\hline MALAT1 & PNPO & pos & 30982780 & mir-29b & Hsp47 & neg & 25744716 \\
\hline MALAT1 & SRSF1 & pos & 28652379 & mir-100 & SMARCA5 & neg & 25217527 \\
\hline MALAT1 & TEAD1 & neg & 30349115 & mir-100 & SMARCD1 & neg & 25217527 \\
\hline MALAT1 & VEGFA & pos & 28652379 & mir-100 & mTOR & neg & 28741069 \\
\hline mir-100 & BMPR2 & neg & 25217527 & mir-100 & VEGFA & neg & 28741069 \\
\hline mir-200b & ARHGAP18 & neg & 28619708 & mir-10b & BCL2L11 & neg & 26359455 \\
\hline mir-200b & ZEB1 & neg & 25972084 & mir-10b & DYRK1A & neg & 27569213 \\
\hline mir-200b & ZEB2 & neg & 25972084 & mir-10b & HOXD10 & neg & 25428807 \\
\hline mir-200b & Sec23a & neg & 25401471 & mir-10b & HOXD10 & neg & 26359455 \\
\hline mir-200b & ZEB2 & neg & 25401471 & mir-10b & HOXD10 & neg & 27569213 \\
\hline
\end{tabular}

Table $\mathbf{2}$ List of ncRNA-target and the type of interaction present in the network (Continued) 
Table 2 List of ncRNA-target and the type of interaction present in the network (Continued)

\begin{tabular}{|c|c|c|c|}
\hline ncRNA & Direct target & Direct effect* & PMID \\
\hline mir-10b & KLF4 & neg & 25428807 \\
\hline mir-10b & PTEN & neg & 27113763 \\
\hline mir-10b & PTEN & neg & 27569213 \\
\hline mir-10b & Tbx5 & neg & 27569213 \\
\hline mir-10b & AKT1 & pos & 27113763 \\
\hline mir-125a & HDAC5 & neg & 25531695 \\
\hline mir-125a & HER2 & neg & 30068375 \\
\hline mir-125a & HER3 & neg & 30068375 \\
\hline mir-125b & HER2 & neg & 25388283 \\
\hline mir-125b & HER2 & neg & 30068375 \\
\hline mir-125b & HER3 & neg & 30068375 \\
\hline mir-146a & FN1 & neg & 30622118 \\
\hline mir-146a & IRAK1 & neg & 25712342 \\
\hline mir-146a & TRAF6 & neg & 25712342 \\
\hline mir-146a & NF-KB1 & neg & 25712342 \\
\hline mir-181a & MMP-14 & neg & 25977338 \\
\hline mir-181a & TUSC3 & neg & 28288641 \\
\hline mir-182 & Palladin & neg & 27641360 \\
\hline mir-182 & SMAD7 & neg & 27996004 \\
\hline mir-196a & HOXB7 & neg & 26180042 \\
\hline mir-196a & SPRED1 & neg & 29685157 \\
\hline mir-196a & HER2 & neg & 26180042 \\
\hline mir-200a & $\operatorname{Sec} 23 a$ & neg & 25401471 \\
\hline mir-200a & ZEB1 & neg & 25972084 \\
\hline mir-200a & ZEB2 & neg & 25401471 \\
\hline mir-200a & ZEB2 & neg & 25972084 \\
\hline mir-200b & ARHGAP18 & neg & 28619708 \\
\hline mir-200b & ZEB1 & neg & 25972084 \\
\hline mir-200b & ZEB2 & neg & 25972084 \\
\hline mir-29b & PIK3R1 & neg & 25622979 \\
\hline mir-29c & Hsp47 & neg & 25744716 \\
\hline mir-29c & TET2 & neg & 29109788 \\
\hline mir-30a & $\mathrm{CDH} 11$ & neg & 30042152 \\
\hline mir-30a & ITGA5 & neg & 30042152 \\
\hline mir-30a & ITGB3 & neg & 30042152 \\
\hline mir-30a & ZEB2 & neg & 29666469 \\
\hline mir-30e & $\mathrm{CDH} 11$ & neg & 30042152 \\
\hline mir-30e & EIF5A2 & neg & 29560860 \\
\hline mir-30e & ITGA5 & neg & 30042152 \\
\hline mir-30e & ITGB3 & neg & 30042152 \\
\hline mir-30e & SCA1 & neg & 29560860 \\
\hline mir-30e & TUSC3 & neg & 28288641 \\
\hline mir-34a & AGO2 & neg & 29941603 \\
\hline
\end{tabular}

Table 2 List of ncRNA-target and the type of interaction present in the network (Continued)

\begin{tabular}{llll}
\hline ncRNA & Direct target & Direct effect* & PMID \\
\hline mir-34a & SRC & neg & 26676753 \\
mir-34a & C22ORF28 & neg & 29187905 \\
mir-34a & eEF2K & neg & 29748184 \\
mir-34a & FOXM1 & neg & 29748184 \\
mir-34a & GFRA3 & neg & 28356515 \\
mir-34a & MCT-1 & neg & 30885232 \\
mir-34a & NOTCH1 & neg & 25368020 \\
mir-34a & tRNAiMET & neg & 29941603 \\
mir-9 & ONECUT2 & neg & 31118200 \\
mir-9 & STARD13 & neg & 27402080 \\
mir-9 & PDGFRB & pos & 27402080 \\
mir-96 & FOXO1 & neg & 27170187 \\
mir-96 & FOXO1 & neg & 29792692 \\
mir-96 & Palladin & neg & 27641360 \\
NEAT1 & FOXN3 & pos & 28805661 \\
NEAT1 & GATA3 & neg & 28805661 \\
NEAT1 & JAM1 & neg & 25417700 \\
NEAT1 & MIR204 & neg & 30803129 \\
NEAT1 & SIN3A & pos & 28805661 \\
UCA1 & MIR122 & neg & 29669595 \\
UCA1 & SLUG & pos & 29774079 \\
\hline * pos positive interaction activation, neg negative interaction, repression
\end{tabular}

\section{The LINC0511-HOTAIR subnetwork}

The intergenic non-protein coding RNA 00511 (LINC00511) participates in a subnetwork with HOTAIR (HOX transcript antisense RNA), which is linked to the methyltransferase EZH2 and causes impaired cell proliferation and inhibition of apoptosis in estrogen receptor (ER) negative $\mathrm{BC}$ cells [154]; indeed, LINC00511 promotes metastasis dissemination by silencing NLK [155]. In this subnetwork LINC00511 was proposed to function as a competitive endogenous RNA, sequestering miR-185, with the effect of inducing E2F1 expression, ultimately leading to stemness and tumorigenesis in all $\mathrm{BC}$ subtypes [80]. The other subnetwork member HOTAIR, can act as a scaffold for the late endosomal/lysosomal adaptor, MAPK and MTOR activator 5 (HBXIP), which promotes the expression of three MYC targets, i.e. CCNA1, EIF4E and LDHA, as well as of the lysine demethylase 1A (LSD1), recruited by HBXIP itself [156]. A novel isoform of HOTAIR, named HOTAIR-N, was observed in association with an increase of invasion and metastasis in laminin-rich extracellular matrix-based threedimensional organotypic cultures (lrECM 3D), compared with traditional "Claudin-low" culture. HOTAIR-N, once 
Table 3 List of non-codingRNAs, their targets and the type of interactions, cited by only one scientific article, and therefore excluded from the network illustrated in Fig. 1 and further described and discussed in the main text of the review

\begin{tabular}{|c|c|c|c|c|}
\hline Non-coding RNA & Target & Type of interaction* & PMID & Reference \\
\hline AC0269041 & SNAI2 & pos & 29774079 & {$[1]$} \\
\hline AGAP2-AS1 & MyD88 & pos & 30157918 & {$[2]$} \\
\hline $\mathrm{Ai}-\mathrm{EGOT}$ & ITPR1, HNRNPH1 & pos & 30999914 & {$[3]$} \\
\hline AK023948 & AKT1 & pos & 28176758 & {$[4]$} \\
\hline ANCR & $\mathrm{EZH} 2$ & neg & 27716745 & {$[5]$} \\
\hline ARNILA & miR-204 & neg & 29844570 & {$[6]$} \\
\hline ASncmtRNA-1 & CCNB1, CCND1, CDK1, CDK4, BIRC5 & pos & 31142736 & {$[7]$} \\
\hline BCYRN1 & BCL2L1 & pos & 27277684 & {$[8]$} \\
\hline BORG & RPAIN & pos & 30467380 & {$[9]$} \\
\hline CASIMO1 & SQLE & pos & 29765154 & [10] \\
\hline CCAT1 & miR-148a/152, miR-204, ANXA2, miR-211 & neg & 31695775 & [11] \\
\hline circ_0025202 & miR-182-5p, FOXO3 & neg & 31153828 & {$[12]$} \\
\hline circAGFG & $\operatorname{miR}-195-5 p$ & neg & 30621700 & [13] \\
\hline circANKS1B & miR-148a, miR-152 & neg & 30454010 & [14] \\
\hline circEPSTI1 & miR-4753, miR-6809 & neg & 30083277 & {$[15]$} \\
\hline circFoxo3 & $\mathrm{FOXO3}$ & pos & 27886165 & [16] \\
\hline CircGFRA1 & miR-34a & pos/neg & 29037220 & {$[17]$} \\
\hline CirclRAK3 & miR-3607 & neg & 29803789 & [18] \\
\hline circKIF4A & miR-375 & neg & 30744636 & [19] \\
\hline CYTOR & mTOR, GOLPH3, KIF14, PRKCA, SMYD3 & pos & 27617288 & [20] \\
\hline DANCR & RXRA, PIK3CA & pos & 30518934 & [21] \\
\hline DSCAM-AS1 & HNRNPL & pos & 27666543 & [22] \\
\hline $\begin{array}{l}\text { EFNA3 (NC1 and } \\
\text { NC2) }\end{array}$ & EFNA3 & pos & 25023702 & [23] \\
\hline ELAV1 & CD133 & neg & 27197265 & [24] \\
\hline EPB41L4A-AS2 & RARRES1 & pos & 30764831 & {$[25]$} \\
\hline EPIC1 & CDC45, CDC20, CCNA2, CDKN1A & pos & 29622465 & [26] \\
\hline Esrp2-as & ESRP2 & pos & 28759043 & {$[27]$} \\
\hline FGF13-AS1 & MYCBP, IGF2BP & neg & 30771425 & {$[28]$} \\
\hline FN1 & miR-200c & neg & 30967542 & [29] \\
\hline GAS5 & miR-222 & neg & 29969658 & {$[30]$} \\
\hline IRAIN & IGF1R & neg & 30195750 & {$[31]$} \\
\hline LncKLHDC7B & KLHDC7B & pos & 30648789 & [32] \\
\hline let-7a & BCL2L1 & neg & 26915294 & [33] \\
\hline LINC00673 & miR-515-5p & neg & 31623640 & {$[34]$} \\
\hline LINC00968 & WNT2 & neg & 30791958 & {$[35]$} \\
\hline LINC01125 & LXR-623 & pos & 30867411 & [36] \\
\hline LINC01133 & KLF4 & pos & 31283068 & {$[37]$} \\
\hline LINC01355 & CCDN1, FOXO3 & neg & 31243265 & [38] \\
\hline LINC01638 & MYCBP & pos & 30002443 & [39] \\
\hline LINC02582 & USP7 & neg & 31601781 & [40] \\
\hline LINCIN & $\begin{array}{l}\text { NF90 (a major spliced form of interleukin enhancer binding factor 3, ILF3) } \\
\text { CDKN1A }\end{array}$ & pos, neg & 28558830 & [41] \\
\hline LINCK & RSL1D1, ZEB1, ZO-1, CDH1/E-cadherin, CDH2/N-cadherin, VIM & pos, pos, neg, neg, pos, & 30795783 & [42] \\
\hline
\end{tabular}


Table 3 List of non-codingRNAs, their targets and the type of interactions, cited by only one scientific article, and therefore excluded from the network illustrated in Fig. 1 and further described and discussed in the main text of the review (Continued)

\begin{tabular}{|c|c|c|c|c|}
\hline Non-coding RNA & Target & Type of interaction* & PMID & Reference \\
\hline & & pos & & \\
\hline $\begin{array}{l}\text { LINCRNA-APOC1P1- } \\
3\end{array}$ & TUBA1A & pos & 27228351 & [43] \\
\hline LINC-RoR & DUSP7 & neg & 29041978 & [44] \\
\hline LINC-ZNF469-3 & miR-574-5p & pos & 29755127 & {$[45]$} \\
\hline LINP1 & IGFBP3 & pos & 30725116 & [46] \\
\hline LnCATB & miR-200, TWIST1 & neg & 30518916 & {$[47]$} \\
\hline Lnc-BM & JAK2/STAT & pos & 29130936 & [48] \\
\hline $\begin{array}{l}\text { IncRNA152, } \\
\text { IncRNA67 }\end{array}$ & $\mathrm{E} 2 \mathrm{~F} 4$ & pos & 26236012 & [49] \\
\hline IncRNA-Hh & GAS1 & pos & 26418365 & [50] \\
\hline LOC284454 & COL2A1, COL4A1 COL6A1, ITGA2 & neg & 29227193 & {$[51]$} \\
\hline MAYA & MST1, YAP1 & pos & 28114269 & [52] \\
\hline MBNL1 & DBNL, TACC & neg & 26883358 & [53] \\
\hline MEG3 & TGFB, TGFBR1, SMAD2 & neg & 26205790 & [54] \\
\hline MIR100HG & CDKN1B & pos & 30042378 & [55] \\
\hline miR-101 & POMP & neg & 26145175 & {$[56]$} \\
\hline miR-103, miR-107 & NKILA & neg & 25759022 & {$[57]$} \\
\hline miR-105 & MXI1 & neg & 29588351 & {$[58]$} \\
\hline miR-106b & BRMS1L & neg & 25406648 & [59] \\
\hline miR-1204 & VDR & neg & 29555976 & {$[60]$} \\
\hline miR-122 & PKM & neg & 25621950 & {$[61]$} \\
\hline miR-124 & IL-11 & neg & 29343249 & {$[62]$} \\
\hline miR-1254 & CCAR1 & neg & 27002217 & [63] \\
\hline miR-1285, miR-136 & HERC4 & neg & 30710319 & {$[64]$} \\
\hline miR-130a & PTEN & neg & 28935812 & {$[65]$} \\
\hline miR-132, miR-212 & SOX4 & neg & 26377202 & {$[66]$} \\
\hline miR-135 & RUNX2 & neg & 25634212 & {$[67]$} \\
\hline miR-135a1 & ESR1, ESRRA, NCOA1 & neg & 29945962 & {$[68]$} \\
\hline miR-138 & $\mathrm{EZH} 2$ & neg & 25339353 & [69] \\
\hline miR-139 & MAT2A, POLQ, TOP1, TOP2A, XRCC5 & neg & 29180477 & [70] \\
\hline miR-141 & TCF12 & neg & 26068592 & [71] \\
\hline miR-142 & APC & neg & 25406066 & [72] \\
\hline miR-144 & TET2, EIF5A2, ATXN2 & neg & 29109788 & [73] \\
\hline miR-148a & DKK1 & neg & 29721077 & [74] \\
\hline miR-148b & ITGA5, ALCAM & neg & 27328731 & [75] \\
\hline miR-15 & $\mathrm{BCL} 2$ & neg & 26915294 & [33] \\
\hline miR-153 & KLF5 & neg & 26941846 & [76] \\
\hline miR-155 & miR-143 & pos & 26795347 & [77] \\
\hline miR-159 & TCF7 & neg & 26794868 & [78] \\
\hline miR-181c & PDPK1 & neg & 25828099 & [79] \\
\hline miR-185 & E2F1 & neg & 30482236 & {$[80]$} \\
\hline miR-18a & SREBF1 & neg & 29988076 & [81] \\
\hline miR-190 & SMAD2 & neg & 29510731 & [82] \\
\hline
\end{tabular}


Table 3 List of non-codingRNAs, their targets and the type of interactions, cited by only one scientific article, and therefore excluded from the network illustrated in Fig. 1 and further described and discussed in the main text of the review (Continued)

\begin{tabular}{|c|c|c|c|c|}
\hline Non-coding RNA & Target & Type of interaction* & PMID & Reference \\
\hline miR-195 & ONECUT2 & neg & 31118200 & [83] \\
\hline miR-199a & LCOR & neg & 28530657 & {$[84]$} \\
\hline miR-200c/141 & HIPK1 & neg & 30613263 & [85] \\
\hline miR-204 & PIK3CB & neg & 30737233 & [86] \\
\hline miR-206 & TWF1, MAP 3 K9, SPATA6, IL-11 & neg, pos, pos, pos & 27435395 & {$[87]$} \\
\hline miR-20a & MAPK1 & neg & 29125598 & [88] \\
\hline miR-21 & DDX5, PTEN & pos & 30413718 & [89] \\
\hline MIR210HG & miR-1226-3p & neg & 31399552 & {$[90]$} \\
\hline miR-214 & miR-148b & neg & 27328731 & {$[75]$} \\
\hline miR-216b-5p & PNPO & neg & 30982780 & [91] \\
\hline miR-218 & ZFX & neg & 31310241 & [92] \\
\hline miR-221 & Beclin1 & neg & 27940575 & [93] \\
\hline miR-24 & ING5 & neg & 28490335 & [94] \\
\hline miR-31 & GNA13 & neg & 25889182 & {$[95]$} \\
\hline miR-320b & NRP1, ETS2 & neg & 26178901 & [96] \\
\hline miR-329, miR-362 & BCAR1 & neg & 26337669 & [97] \\
\hline miR-33a & ADAM9, ROS1 & neg & 26507842 & [98] \\
\hline miR-345 & KISS1 & neg & 28981380 & [99] \\
\hline miR-34c & EIF5A2, SCA2 & neg & 29560860 & [100] \\
\hline miR-3609, miR-5096 & CDK1 & neg & 31142736 & [7] \\
\hline miR-375 & TNS3, PXN, CCL2 & neg & 30850595 & [101] \\
\hline miR-424 (322)/503 & $\mathrm{BCL2}$, IGF1R & neg & 28404630 & [102] \\
\hline miR-4306 & SIX1, CDC42, VEGFA & neg & 30867840 & [103] \\
\hline miR-4485-3p & CCNB1, CCND1 & neg & 31142736 & [7] \\
\hline miR-454-3p & RPRD1A, AXIN2, DKK3, SFRP1 & neg & 30809286 & [104] \\
\hline miR-4728 & ESR1 & neg & 29476008 & [105] \\
\hline miR-4766-5p & SIRT1 & neg & 29752439 & [106] \\
\hline miR-484 & CDA & neg & 25643696 & [107] \\
\hline miR-515 & NRAS, MARK4, PIK3CB & neg & 26882547 & [108] \\
\hline miR-548a & SIX1 & neg & 29455928 & [109] \\
\hline miR-548j & Tensin1 & neg & 26949125 & [110] \\
\hline miR-5582-3p & LUCAT1, TCF7 & neg & 31300015 & [111] \\
\hline miR-600 & SCD1 & neg & 28249169 & [112] \\
\hline miR-892b & NF-kB, TRAF2, TAB3, TAK1 & neg & 26747895 & [113] \\
\hline miR-93 & NCOA3 & neg & 28920955 & [114] \\
\hline miR-940 & ARHGAP1, FAM134A & neg & 29440427 & {$[115]$} \\
\hline miR-99a & Her2 & neg & 25388283 & [116] \\
\hline MPPED2-AS1 & DNMT1, MPPED2 & neg & 31181813 & [117] \\
\hline NAMPT-AS & POU2F2 & pos & 30940661 & [118] \\
\hline NBR2 & AMPK & pos & 26999735 & [119] \\
\hline NDRG1-OT1 & NDRG1 & neg & 30497328 & [120] \\
\hline NKILA & $\mathrm{lk}-\mathrm{B}$ & neg & 25759022 & {$[57]$} \\
\hline NONHSAT101069 & miR-129-5p & neg & 31444414 & [121] \\
\hline
\end{tabular}


Table 3 List of non-codingRNAs, their targets and the type of interactions, cited by only one scientific article, and therefore excluded from the network illustrated in Fig. 1 and further described and discussed in the main text of the review (Continued)

\begin{tabular}{|c|c|c|c|c|}
\hline Non-coding RNA & Target & Type of interaction* & PMID & Reference \\
\hline NORAD & $\mathrm{S} 100 \mathrm{P}$ & neg & 30967631 & {$[122]$} \\
\hline PDCD4-AS1 & PDCD4 & pos & 30496290 & [123] \\
\hline piR-FTH1 & Fth1 & neg & 30102404 & [124] \\
\hline PIWI-36712 & SEPW1P & neg & 30636640 & [125] \\
\hline PIWIL3 & miR-21, miR-45 & neg & 28094937 & {$[126]$} \\
\hline PNUTS & miR-205, ZEB1, ZEB2 & neg, pos, pos & 28825698 & [127] \\
\hline PRLB & SIRT1 & pos & 29752439 & [106] \\
\hline PTENP1 & miR-20a, PTEN & neg, pos & 31196157 & [128] \\
\hline PTV1 & BAP-1, CTNNB1 & pos & 29760406 & [129] \\
\hline PYCARD-AS1 & DNMT1, G9 & pos & 31086376 & [130] \\
\hline RAINs & RUNX2 & pos & 28981843 & [131] \\
\hline RP1 & p27 & neg & 31073122 & [132] \\
\hline SNHG5 & miR-154-5p & neg & 31255976 & [133] \\
\hline SPRY4-IT1 & ZNF703 & pos & 25742952 & [134] \\
\hline ST8SIA6-AS1 & PLK1, AURORA & pos & 31286138 & [135] \\
\hline T3p & RISC, NUPR1, PANX2 & neg, pos, pos & 30397354 & [136] \\
\hline TINCR & HER-2, miR-125b, Snail1 & Pos, neg, pos & 30621694 & [137] \\
\hline TROJAN & ZMYND8, ZNF592 & neg & 30854423 & [138] \\
\hline WDR7-7 & GPR30 & pos & 29096683 & [139] \\
\hline XIST & c-Met, miR-503 & neg, pos & 30028120 & [140] \\
\hline YIYA & CDK6, PFKFB3 & pos & 29967256 & [141] \\
\hline
\end{tabular}

*pos positive interaction, activation, neg negative interaction, repression

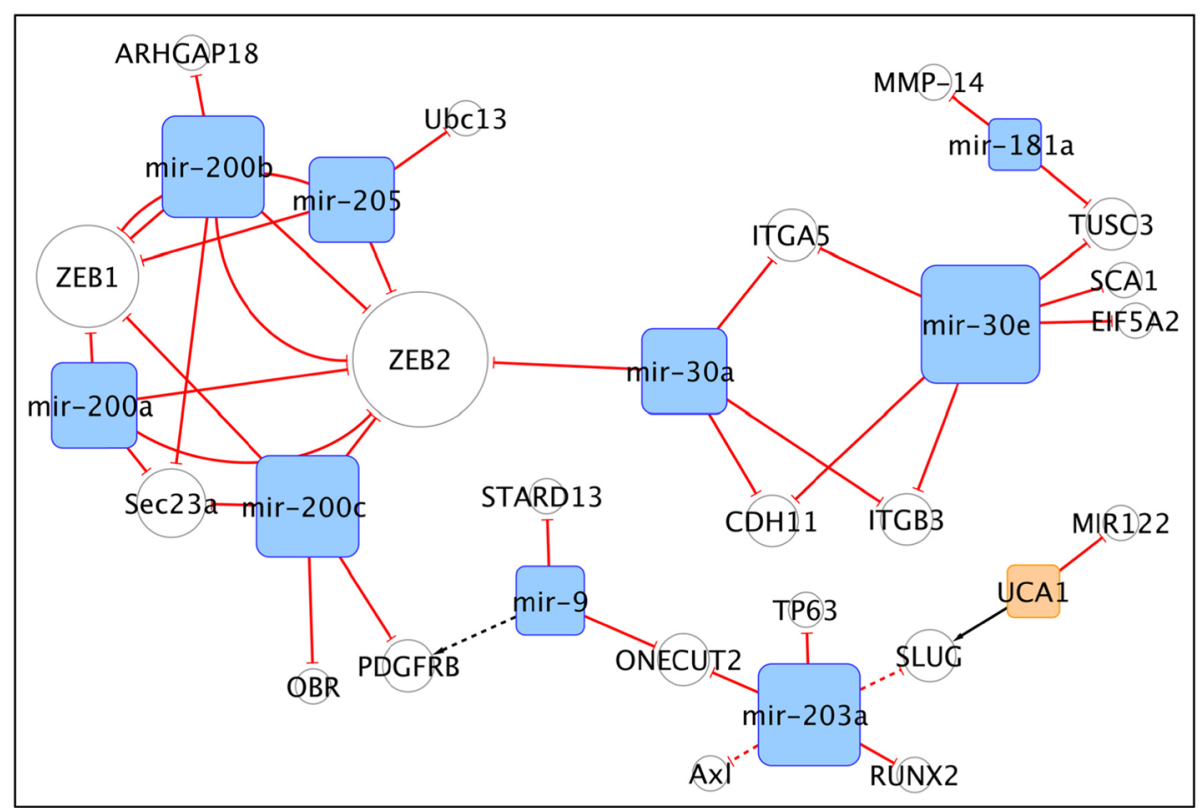

Fig. 2 The miR-200 s/ZEB2 cliche 
cells are attached to extracellular matrix, binds BRD4, a reader of histone markers that recognizes trimethylation on histone H3 lysine 4 [157].

\section{The H19/LINK-A/MIR2052HG/miR-25/miR-10b/ Eleanor sub-network}

This relatively large sub-network is depicted in Fig. 3. LncH19 and Long intergenic non-coding RNA for kinase activation 01139 (LINK-A) are both indirectly involved in the regulation of the expression of HIF1A. In particular, H19 could induce CSC properties and tumorigenesis possibly via LIN28 by acting as a competitive endogenous RNA towards let-7 miRNA. Furthermore, $\mathrm{H} 19$ can indirectly stimulate the expression of HIF1A and PDK1, thus promoting the glycolysis pathway, a crucial step in CSC reprogramming.

H19 and PDK1 therefore may represent possible therapeutic targets, to contrast glycolysis and cancer stemlike properties $[158,159]$. Consistently, LINK-A is involved in the normoxic HIF1A stabilization pathway, through the recruitment of the protein tyrosine kinase 6 (BRK) and of LRRK2, that phosphorylate and activate HIF1A itself. From a functional point of view, LINK-A is associated with glycolysis reprogramming in TNBC and promotes tumorigenesis [160]. H19 promotes tamoxifen resistance and autophagy in MCF7 cells, by downregulating Beclin-1 methylation via epigenetic mechanisms. In details, H19 inhibits adenosylhomocysteinase (SAHH), with subsequent acyl-CoA synthetase medium chain family member 3 (SAH) accumulation, which in turn inhibits Beclin-1 promoter methylation by DNMT3B. Therefore the H19/SAHH/DNMT3B axis was proposed as a therapeutic target against tamoxifen resistance [161]. LINK-A is further connected with MIR2052HG, miR-25 and miR-10b, all known activators of AKT1. In this subnetwork a single nucleotide polymorphism (SNP), rs12095274: A > G, in LINK-A affects the phosphorylation status of AKT1 and is associated with AKT inhibitorresistance by AKT-PREX1 interactions, which results in a worse prognosis for patients [162]. Also MIR2052HG presents a SNP (rs13260300), which have been associated with a higher recurrence of $\mathrm{BC}$ and resistance to aromatase inhibitors. MIR2052HG positively regulates estrogen receptor alpha $(\mathrm{ER} \alpha)$ via the AKT/FOXO3 pathway, and limiting ER $\alpha$ ubiquitination [163]. MIR2052HG has shown to regulate ER $\alpha$ expression by: i) promoting the recruitment of EGR1 on LMTK3 promoter with reduction of PKC activity, indirectly enhancing ER $\alpha$ protein levels; ii) limiting $\mathrm{ER} \alpha$ ubiquitination via PKC/MEK/ERK/RSK1 pathway. Both mechanisms have been identified as active in the presence of the MIR2052HG SNP rs13260300 and of aromatase inhibitors in ER $\alpha$-positive BC [164]. MiR-25 can promote cell proliferation in TNBC by silencing B-cell translocation gene 2 (BTG2) and, indirectly, by the activation of AKT and ERK-MAPK pathways [165]. Additionally it has been reported that miR-25 interacts with miR-93 (not present in this network), to down-regulate CGAS, by targeting NCOA3 at its promoter. Hence, it could determine immune evasion and accelerated cell cycle progression under hypoxia in Luminal A cells [114].

The other microRNA engaged in this network is miR10b which targets HOXD10 and KLF4 to play a prooncogenic role. It can promote cell invasion and metastasis formation in the TNBC subtype through its secretion via exosomal vesicles, mediated by neutral sphingomyelin phosphodiesterase 2 (nSMase) indeed and it is capable of transforming non malignant HMLE

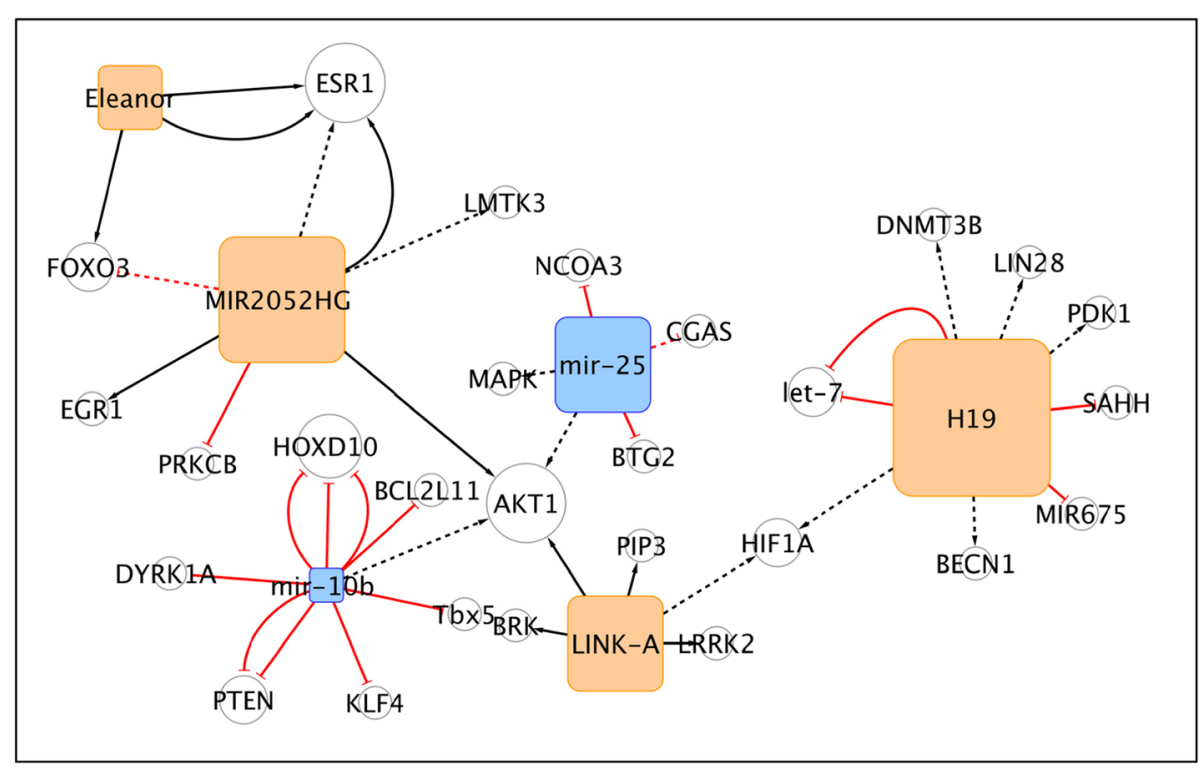

Fig. 3 The H19/LINK-A/MIR2052HG/miR-25/miR-10b/Eleanor sub-network 


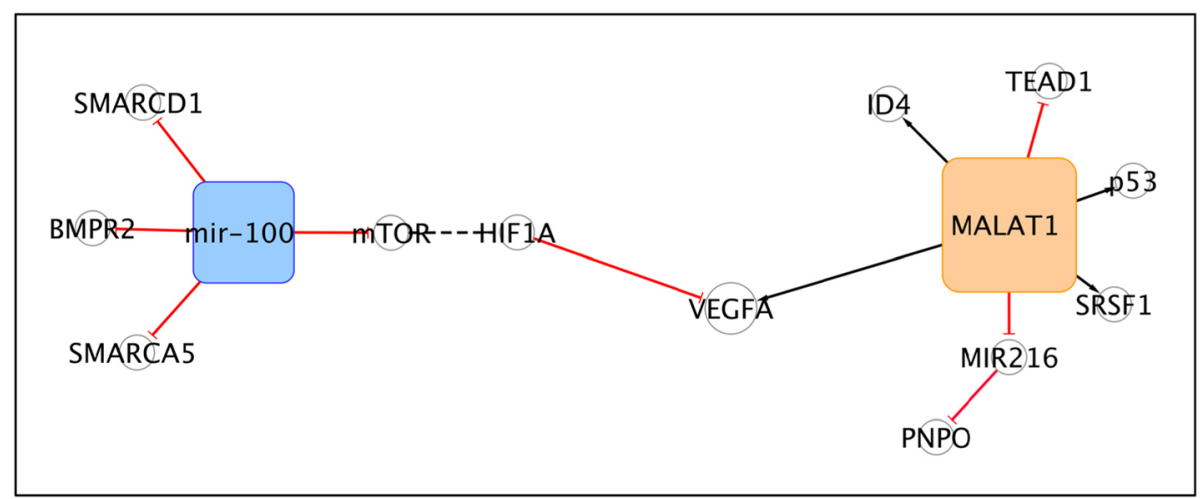

Fig. 4 The MALAT1/miR-100 sub-network

cells into cells with invasion-ability [166]. Metastasis generation and self-renewal of CSCs driven by miR-10b are the results of the directly inhibition of miRNA target, PTEN, and the indirectly increase of the expression of AKT [167], as well as that of HOXD10 and BCL2 like 11(BIM) [168].

For this reason, miR-10b has been proposed as a "metastamiR", re-asserted by Kim and co-workers who focused on its targets onco-suppressors Tbx, PTEN, DYRK1A and the anti-metastatic gene HOXD10 [169]. Finally, Eleanor also plays a role in the cluster of non-coding RNAs, cisactivating both ESR1 and FOXO3 [170]. The inhibition of Eleanor could represent a key to switch off topologically associating domain (TAD) containing proteins and to target cells resistant to endocrine therapy [171].

\section{The MALAT1/miR-100 partnership}

The sub-network shown in Fig. 4 evidences long noncoding MALAT1 and miR-100. These non-coding RNAs are indirectly interconnected by VEGFA. MALAT1 modulates VEGFA isoforms expression enhancing TP53 mutations in basal-like BC subtype (BLBC). The interaction between MALAT1 and mutant TP53/ID4 is mediated by SRSF1 splicing factor and promotes MALAT1 delocalization from nuclear speckles and its recruitment on VEGFA pre-mRNA [172].. In addition, MALAT1 acts as competitive endogenous RNA to sponge miR-216b, thus restoring the expression of PNPO, which is associated with promoted cell proliferation, migration and invasion in invasive ductal carcinoma (IDC). MALAT1/ miR-216/PNPO pro-metastatic axis represents a target for molecular therapy, as validated in Luminal A and TNBC subtypes [91]. However the role of MALAT1 is still debated. Other studies reported that MALAT1 inhibits the transcription of the pro-metastatic factor TEAD, hindering the interaction between the YAP1 at the TEAD promoters; suggesting MALAT1 as a metastasis-suppressing factor in BLBC [173]. The transfer of miR-100 via MSC-derived exosomes in cancer cells determines the down-regulation of VEGFA secretion by directly targeting mammalian target of rapamycin (mTOR) and modulating mTOR/HIF- $1 \alpha$ axis, in fact the miR-100 up-regulation could inhibit angiogenesis and endothelial cell proliferation in the $\mathrm{BC}$ microenvironment [174].

Furthermore, mir-100 is negatively correlated with CSC-like self-renewal by inhibiting the SMARCA5, SMARCD1 and BMPR2 regulatory genes in TNBC and Luminal A subtypes. The miR-100 involvement in the inhibition of metastasis has also been validated in vivo [175].

\section{The miR-125a/b-miR196 sub-network}

Figure 5 shows the miR-125/HER2 subnetwork. MiR$125 \mathrm{a} / \mathrm{b}$ target the 3'UTR region of both HER2 which elevates HER3 expression levels, thus reducing HER2 mRNA levels and consequently their oncogenic effects in cellular models, including increase of tumour growth rates and trastuzumab resistance [176]. Consistently, the loss of miR-125b promotes HER2 signalling, and is

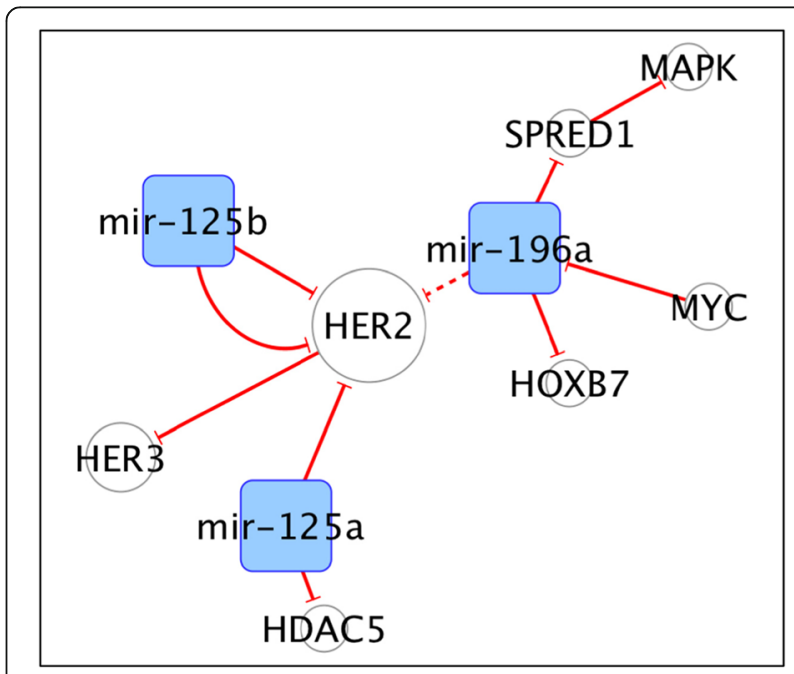

Fig. 5 The miR125/HER2 subnetwork 
associated with poor prognosis in patients with Luminal A tumours [116]. MiR-125a exerts also a crucial role in the regulation of apoptosis by silencing of HDAC5, upon stimulation of the RUNX3/p300 pathway, representing a novel anticancer strategy able to activate caspase 3/9 [177]. Indirectly, also miR-196 contributes to inhibit HER2 expression, by altering HOXB7 and HOXB7-ER $\alpha$ interaction. Nevertheless, miR-196 is down-regulated by MYC, which restores HOXB7 and promotes Luminal A breast cancer tumorigenesis and tamoxifen resistance [178]. On the contrary, Jiang et al. demonstrated that miR-196a, upon stimulation by ER- $\alpha$ interaction, promotes growth of Luminal A breast cancer inhibiting SPRED1, a negative regulator of the RAS/RAF/MAPK signalling, indirectly activated by miR-196 [179].

\section{The miR-182 and miR-96 microRNAs}

A study by $\mathrm{Yu}$ et al. focuses on the pro-metastatic miR182, which is associated with EMT, invasion, as well as distant metastasis formation. MiR-182 inhibits the expression of SMAD7, which is both a transcriptional target of TGF $\beta$ and a negative regulator of TGF $\beta$ signalling [180]. Also, miR-96 modulates the pro-apoptotic FOXO1, a relevant target for precision therapies, and inspired the rational design of TargaprimiR-96 [181]. As a proof of concept, the development of a conjugate small molecule that selectively binds the oncogenic miR-96 hairpin precursor (RIBOTACs), is able to recruit a latent endogenous ribonuclease (RNase L) to FOXO1 transcript, inducing its cleavage. Functionally the silencing of miR-96 de-repressed FOXO1 and induced apoptosis exclusively in TNBC [182]. Other articles highlight an opposite role for these two miRNAs. MiR-96 and miR-182 both target the 3'-UTR region of the PALLD gene. Down-modulation of Palladin transcript expression leads both to decreased migration and invasion of Luminal A breast tumour cells. However, when it is present rs1071738 SNP, a common functional variant of PALLD gene, at the miR-96/miR-182-binding site, the 3'UTR fails to bind the target microRNAs, compromising cell invasion, as verified in in vitro experiments [183].

\section{miR29b and miR-29c}

MiR-29b and miR-29c both target chaperone Hsp47, a modulator of the extracellular matrix (ECM) and promoter of $\mathrm{BC}$ development; their indirect regulation of ECM genes reduces collagen and fibronectin deposition [184].

In addition, miR-29c targets TET2, thus inhibiting the metastatic phenotype and the genome instability induced by the conversion of 5-methylcitosine $(5-\mathrm{mC})$ to 5 hydroxymethylcytosine $(5-\mathrm{hmC})$. Nevertheless, in TNBC this condition is antagonized by the lymphoid specific helicase (LSH), which induces miR-29c silencing [73].
Interestingly, miR-29b can act as both inhibitor and promoter of cell proliferation, in Luminal A and TNBC subtypes respectively, based on differential regulation of activation of NFkB and TP53 pathway, mediated by S100A7. In MCF7 cells, S100A7 inhibits NFKB signalling with a consequent upregulation of miR-29b that in turn targets CDC42 and PIK3R1 and indirectly activates TP53 leading to the activation of anti-proliferative pathways. In contrast, in MDA-MB-231 cells, miR-29b which has a lower expression than in MCF7 cells, is suppressed by NFkB with consequent repression of TP53 and promotion of metastasis dissemination [185].

\section{Other non-coding RNAs relevant in breast cancer}

In Fig. 1 we showed all sub-networks, whose ncRNAs have been described in at least two different sources from literature.

One of these ncRNAs is the estrogen-inducible long non-coding NEAT1, which has been proposed to act as ceRNA and 'sponge' miR-204. MiR-204 inhibition in turn induced impaired cell proliferation and inhibition of apoptosis. These two processes were supported by the H19 lncRNA [186], to promote para-speckle formation under hypoxia condition, mediated by sequestration of HIF2A and F11 receptor (JAM1) [187]. NEAT1 was also involved in the promotion of invasion, EMT and metastasis dissemination in Luminal A cells by interfering with FOXN3/SIN3A interactions and leading to the repression of GATA3, a crucial regulator of EMT [188].

Another miRNA, miR-27b negatively regulates the acquisition of drug resistance, and is able to induce tumour seeding, two critical properties of CSCs. These effects are mediated by the targeting of ENPP1 and by indirect prevention of the over-expression of ABCG2 transporter. This function was supported by anti-type II diabetes (T2D) drug metformin, that counteracted the generation of CSCs [189]. MiR-27b was also shown to promote the Warburg effect, by inhibiting the PDHX with subsequent dysregulation of the levels of pyruvate, lactate and citrate that increase cell proliferation in the Luminal A and TNBC subtypes [190].

MiR23b has also been subject of recent researches, and itself a notable ncRNA in BC. Its exosome-mediated delivery promoted by Docosahexaenoic acid, an anti-angiogenesis compound, was able to suppress the pro-angiogenic targets PLAU and AMOTL1 in Luminal A and TNBC [96]. Furthermore, in ER-positive endocrine therapy resistant cells, miR-23b was involved in the reprogramming of aminoacid metabolism occurring in association with the downregulation of SLC6A14 aminoacid transporter, the stimulation of autophagy and the import of aspartate and glutamate by SLC1A2 transporter [191].

The IncRNA breast cancer anti-estrogen resistance 4 (BCAR4) is associated with advanced BC and metastasis. 
In response to CCL21 chemokine, BCAR4 binds SNIP1 and protein phosphatase 1 regulatory subunit 10 (PNUTS) activating the non-canonical Hedgehog/GLI2 transcriptional program and promoting cell migration [192]. It has been demonstrated that BCAR4 is also involved in the reprogramming of glucose metabolism mediated by YAP1 and favours the transcription of glycolysis promoters $\mathrm{HK} 2$ and PFKFB3 via Hedgehogsignalling. The activation of YAP1-BCAR4-glycolisis axis is linked with poor prognosis, and represents an interesting therapeutic target for locked nucleic acids (LNA) delivery, as shown by Zheng et al. [193]

In our review, miR-34a appears as the most discussed non-coding RNA, and several independent research groups all pointed it out as an oncosuppressor. MiR-34a, poorly-expressed in TNBC, revealed its antitumorigenic nature by direct targeting of c-SRC [194], GFRA3 [195], and the MCTS1 re-initiation and release factor (MCT-1). Mir-34a also indirectly modulates IL-6, an interleukine associated with breast epithelial acini morphogenesis, and with EMT stimulation in TNBC [196]. Consistently, miR-34a inhibits cancer stem cell properties and promotes doxorubicin sensitivity in MCF7 cells, by targeting NOTCH1. In MCF7 doxorubicin resistant (MCF7/ADR) cells, miR34a is expressed at low level, possibly due to TP53 mutations [197]. Other effects promoted by miR-34a are the cell-cycle arrest and the apoptosis of TNBC by targeting $\mathrm{tRNA}_{\mathrm{i}}{ }^{\mathrm{Met}}$ and AGO2 [198]. Furthermore, miR-34a negatively regulates the EEF2K and FOXM1 proto-oncogenes, both associated with short-term patient survival [199].

The tumour suppressor miR146a, (and its relative miR146b) is up-regulated by FOXP3 and targets IRAK1 and TRAF6 causing NF-kB inactivation in the Luminal A subtype. The FOXP3/miR-146/NF-kB axis limits tumour growth and could be a valuable target for therapy [200]. The role of miR-146a includes the reduction of fibronectin and opposing to the epithelial phenotype in TNBC subtype with a pro-metastatic activity supported via the oncosuppressor WWOX, that antagonizes MYC functions [201].

\section{Conclusions}

The roles of non-coding RNAs in the establishment and evolution of breast cancer are still under scrutiny by many investigators currently active in the field. In this review we performed an unsupervised and large study of the recent literature in the last quinquennium (2014-2019). We used a data-driven approach in order to produce the most unbiased outcome. Orthogonally, we enforced a strict human based curation of each article selection by the PubMed queries. Only papers that clearly applied mechanistic approaches by using in vitro or in vivo methods were

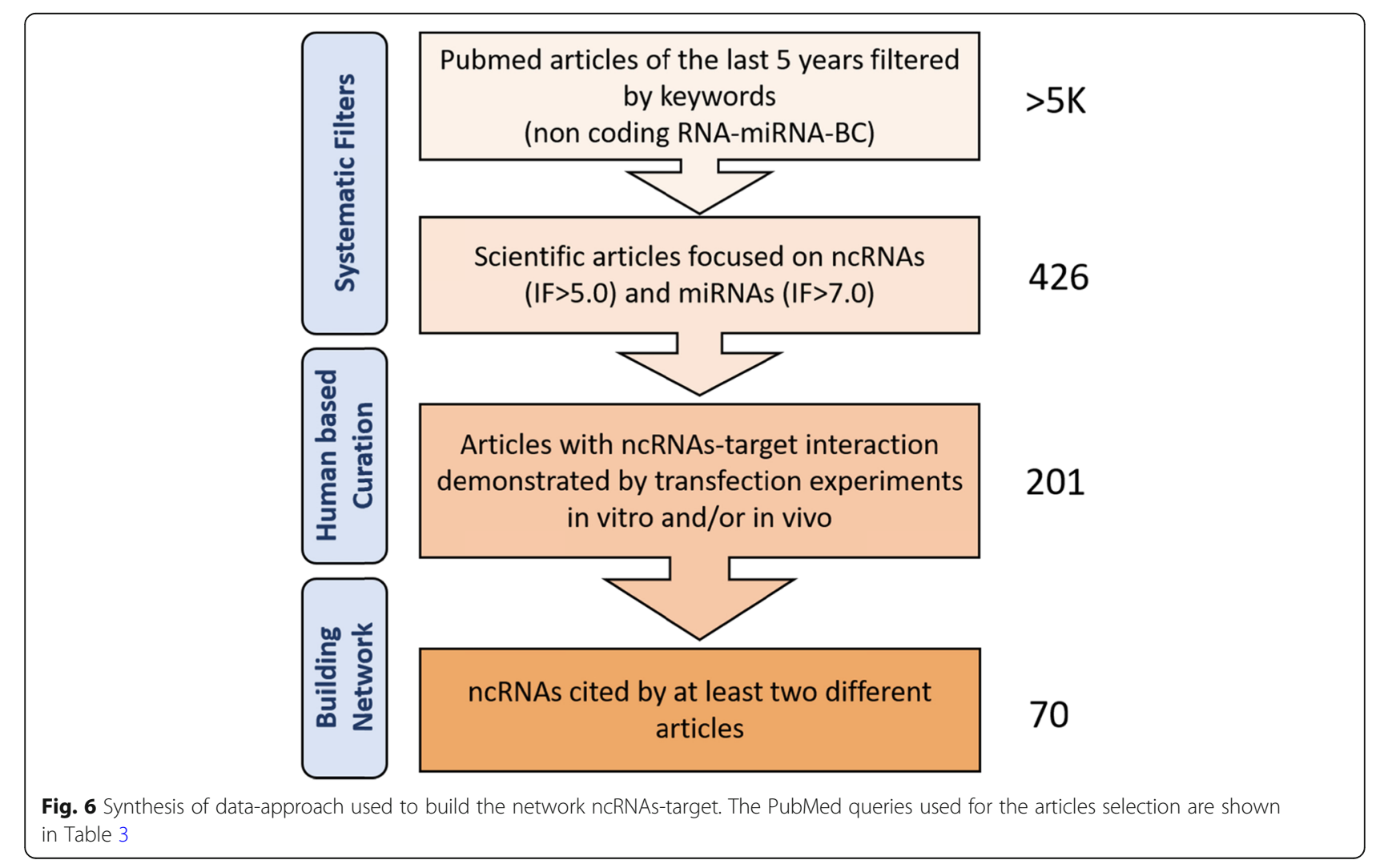


included in this review. Thus, we excluded, and did not report, papers with pure correlative analyses, which albeit revealing would not distinguish a causative action of the non-coding RNAs under scrutiny. All steps of our approach are synthesized in Fig. 6.

\section{Abbreviations}

BC: Breast cancer; BIM: BCL2 like 11; BLBC: Basal like breast cancer; BRK: Protein tyrosine kinase 6; ceRNA: Competing endogenous RNA; circRNA: Circular RNA; CSCs: Cancer stem cells; EMT: Epithelial mesenchymal transition; ER: Estrogen receptor; ETR: Endocrine therapy resistant; EV: Exosomal vesicles; HBXIP: Late endosomal/lysosomal adaptorMAPK and MTOR activator 5; IDC: Invasive ductal carcinoma; IMP1: Insulin-like growth factor 2 messenger RNA binding protein; JAM1: F11 receptor; LINCRNA: Large intergenic non-coding RNAs; LN1: Laminin111; IncRNA: Long noncoding RNAs; LSD1: Lysine demethylase 1A; LSH: Helicase lymphoid specific; MCT-1: MCTS1 reinitiation and release factor; miR: Microrna; ncRNA: Non-coding RNA; nSMase: Sphingomyelin phosphodiesterase 2; PIP3: Phosphatidylinositol3,4,5-trisphosphate dependent Rac exchange factor 1; PNUTS: Protein phosphatase 1 regulatory subunit 10; RNA: Ribonucleic acid; SAH: AcylCoA synthetase medium chain family member 3 ;

SAHH: Adenosylhomocysteinase; SCA1: Ataxin 1; SLUG: Snail family transcriptional repressor 2; SNP: Single nucleotide polymorphism; TNBC: Triple negative breast cancer; UBC13: Ubiquitin conjugating enzyme E2 N

\section{Acknowledgements}

Many thanks to people at LTTA for their constant support.

\section{Authors' contributions}

FC and SV devised the concept; MG, ER, FC, NB, CA and SV read the manuscripts from the literature and performed the manual curation of the selected papers. The author(s) read and approved the final manuscript.

\section{Funding}

thank AIRC for their support throughout the years.

\section{Availability of data and materials}

not applicable

\section{Ethics approval and consent to participate}

not applicable

\section{Consent for publication}

not applicable

\section{Competing interests}

The authors declare that they have no competing interests.

\section{Author details}

'Department of Morphology, Surgery and Experimental Medicine, University of Ferrara, Ferrara, Italy. ${ }^{2}$ LTTA, University of Ferrara, Ferrara, Italy. ${ }^{3}$ Department of Biomedical Sciences and Specialist Surgery, University of Ferrara, 44121 Ferrara, Italy. ${ }^{4}$ RCCS Istituto Ortopedico Galeazzi, Milan, Italy. ${ }^{5}$ Area of Neuroscience, International School for Advanced Studies (SISSA-ISAS), Trieste, Italy.

Received: 3 January 2020 Accepted: 5 March 2020

\section{Published online: 18 March 2020}

\section{References}

1. Li G-Y, Wang W, Sun J-Y, Xin B, Zhang X, Wang T, et al. Long non-coding RNAs AC026904.1 and UCA1: a «one-two punch» for TGF- $\beta$-induced SNAI2 activation and epithelial-mesenchymal transition in breast cancer. Theranostics. 2018;8(10):2846-61.

2. Dong H, Wang W, Mo S, Chen R, Zou K, Han J, et al. SP1-induced IncRNA AGAP2-AS1 expression promotes chemoresistance of breast cancer by epigenetic regulation of MyD88. J Exp Clin Cancer Res. 2018;37(1):202.
3. Xu S, Wang P, Zhang J, Wu H, Sui S, Zhang J, et al. Ai-IncRNA EGOT enhancing autophagy sensitizes paclitaxel cytotoxicity via upregulation of ITPR1 expression by RNA-RNA and RNA-protein interactions in human cancer. Mol Cancer. 2019:18(1):89.

4. Koirala P, Huang J, Ho T-T, Wu F, Ding X, Mo Y-Y. LncRNA AK023948 is a positive regulator of AKT. Nat Commun. 2017;8:14422.

5. Li Z, Hou P, Fan D, Dong M, Ma M, Li H, et al. The degradation of EZH2 mediated by IncRNA ANCR attenuated the invasion and metastasis of breast cancer. Cell Death Differ. 2017;24(1):59-71.

6. Yang $F$, Shen $Y$, Zhang $W$, Jin J, Huang $D$, Fang $H$, et al. An androgen receptor negatively induced long non-coding RNA ARNILA binding to miR204 promotes the invasion and metastasis of triple-negative breast cancer. Cell Death Differ. 2018:25(12):2209-20.

7. Fitzpatrick C, Bendek MF, Briones M, Farfán N, Silva VA, Nardocci G, et al. Mitochondrial ncRNA targeting induces cell cycle arrest and tumor growth inhibition of MDA-MB-231 breast cancer cells through reduction of key cell cycle progression factors. Cell Death Dis. 2019;10(6):423.

8. Singh R, Gupta SC, Peng W-X, Zhou N, Pochampally R, Atfi A, et al. Regulation of alternative splicing of $\mathrm{BCl}-\mathrm{x}$ by $\mathrm{BC} 200$ contributes to breast cancer pathogenesis. Cell Death Dis. 2016;7(6):e2262.

9. Gooding AJ, Zhang B, Gunawardane L, Beard A, Valadkhan S, Schiemann WP. The IncRNA BORG facilitates the survival and chemoresistance of triplenegative breast cancers. Oncogene. 2019;38(12):2020-41.

10. Polycarpou-Schwarz M, Groß M, Mestdagh P, Schott J, Grund SE, Hildenbrand C, et al. The cancer-associated microprotein CASIMO1 controls cell proliferation and interacts with squalene epoxidase modulating lipid droplet formation. Oncogene. 2018;37(34):4750-68.

11. Tang T, Guo C, Xia T, Zhang R, Zen K, Pan Y, et al. LncCCAT1 promotes breast cancer stem cell function through activating WNT/ß-catenin signaling. Theranostics. 2019;9(24):7384-402.

12. Sang Y, Chen B, Song X, Li Y, Liang Y, Han D, et al. CircRNA_0025202 regulates tamoxifen sensitivity and tumor progression via regulating the miR-182-5p/FOXO3a axis in breast cancer. Mol Ther. 2019;27(9):1638-52.

13. Yang $R$, Xing $L$, Zheng $X$, Sun $Y$, Wang $X$, Chen J. The circRNA circAGFG1 acts as a sponge of miR-195-5p to promote triple-negative breast cancer progression through regulating CCNE1 expression. Mol Cancer. 2019;18(1):4.

14. Zeng $\mathrm{K}, \mathrm{He} B$, Yang $\mathrm{BB}, \mathrm{Xu} \mathrm{T}$, Chen $\mathrm{X}, \mathrm{Xu} \mathrm{M}$, et al. The pro-metastasis effect of circANKS1B in breast cancer. Mol Cancer. 2018:17(1):160.

15. Chen $B$, Wei W, Huang $X$, Xie X, Kong Y, Dai D, et al. circEPSTI1 as a prognostic marker and mediator of triple-negative breast cancer progression. Theranostics. 2018;8(14):4003-15.

16. Du WW, Fang L, Yang W, Wu N, Awan FM, Yang Z, et al. Induction of tumor apoptosis through a circular RNA enhancing Foxo3 activity. Cell Death Differ. 2017;24(2):357-70.

17. He R, Liu P, Xie X, Zhou Y, Liao Q, Xiong W, et al. circGFRA1 and GFRA1 act as ceRNAs in triple negative breast cancer by regulating miR-34a. J Exp Clin Cancer Res. 2017:36(1):145

18. Wu J, Jiang Z, Chen C, Hu Q, Fu Z, Chen J, et al. CirclRAK3 sponges miR3607 to facilitate breast cancer metastasis. Cancer Lett. 2018:430:179-92.

19. Tang $H$, Huang $X$, Wang J, Yang L, Kong Y, Gao G, et al. circKIF4A acts as a prognostic factor and mediator to regulate the progression of triplenegative breast cancer. Mol Cancer. 2019;18(1):23.

20. Van Grembergen O, Bizet M, de Bony EJ, Calonne E, Putmans P, Brohée S, et al. Portraying breast cancers with long noncoding RNAs. Sci Adv. 2016; 2(9):e1600220.

21. Tang J, Zhong G, Zhang H, Yu B, Wei F, Luo L, et al. LncRNA DANCR upregulates PI3K/AKT signaling through activating serine phosphorylation of RXRA. Cell Death Dis. 2018;9(12):1167.

22. Niknafs YS, Han S, Ma T, Speers C, Zhang C, Wilder-Romans K, et al. The IncRNA landscape of breast cancer reveals a role for DSCAM-AS1 in breast cancer progression. Nat Commun. 2016;7:12791.

23. Gómez-Maldonado L, Tiana M, Roche O, Prado-Cabrero A, Jensen $L$, Fernandez-Barral $A$, et al. EFNA3 long noncoding RNAs induced by hypoxia promote metastatic dissemination. Oncogene. 2015;34(20):2609-20.

24. Latorre E, Carelli S, Raimondi I, D'Agostino V, Castiglioni I, Zucal C, et al. The ribonucleic complex HUR-MALAT1 represses CD133 expression and suppresses epithelial-mesenchymal transition in breast cancer. Cancer Res. 2016;76(9):2626-36.

25. Pang B, Wang Q, Ning S, Wu J, Zhang X, Chen Y, et al. Landscape of tumor suppressor long noncoding RNAs in breast cancer. J Exp Clin Cancer Res. 2019;38(1):79. 
26. Wang Z, Yang B, Zhang M, Guo W, Wu Z, Wang Y, et al. IncRNA epigenetic landscape analysis identifies EPIC1 as an oncogenic IncRNA that interacts with MYC and promotes cell-cycle progression in cancer. Cancer Cell. 2018;33(4):706-720.e9.

27. Heilmann K, Toth R, Bossmann C, Klimo K, Plass C, Gerhauser C. Genome-wide screen for differentially methylated long noncoding RNAs identifies Esrp2 and IncRNA Esrp2-as regulated by enhancer DNA methylation with prognostic relevance for human breast cancer. Oncogene. 2017;36(46):6446-61.

28. Ma F, Liu X, Zhou S, Li W, Liu C, Chadwick M, et al. Long non-coding RNA FGF13-AS1 inhibits glycolysis and stemness properties of breast cancer cells through FGF13-AS1/IGF2BPs/Myc feedback loop. Cancer Lett. 2019;450:63-75.

29. Liu Y, Xue M, Du S, Feng W, Zhang K, Zhang L, et al. Competitive endogenous RNA is an intrinsic component of EMT regulatory circuits and modulates EMT. Nat Commun. 2019;10(1):1637.

30. Gu J, Wang Y, Wang X, Zhou D, Shao C, Zhou M, et al. Downregulation of IncRNA GAS5 confers tamoxifen resistance by activating miR-222 in breast cancer. Cancer Lett. 2018;434:1-10.

31. Pian L, Wen X, Kang L, Li Z, Nie Y, Du Z, et al. Targeting the IGF1R pathway in breast cancer using antisense IncRNA-mediated promoter cis competition. Mol Ther Nucleic Acids. 2018:12:105-17.

32. Beltrán-Anaya FO, Romero-Córdoba S, Rebollar-Vega R, Arrieta O, Bautista-Piña $V$, Dominguez-Reyes $C$, et al. Expression of long noncoding RNA ENSG00000226738 (LnCKLHDC7B) is enriched in the immunomodulatory triple-negative breast cancer subtype and its alteration promotes cell migration, invasion, and resistance to cell death. Mol Oncol. 2019;13(4):909-27.

33. Adams CM, Eischen CM. Histone deacetylase inhibition reveals a tumorsuppressive function of MYC-regulated miRNA in breast and lung carcinoma. Cell Death Differ. 2016:23(8):1312-21.

34. Qiao K, Ning S, Wan L, Wu H, Wang Q, Zhang X, et al. LINC00673 is activated by $Y Y 1$ and promotes the proliferation of breast cancer cells via the miR-515-5p/MARK4/Hippo signaling pathway. J Exp Clin Cancer Res. 2019:38(1):418

35. Xiu D-H, Liu G-F, Yu S-N, Li L-Y, Zhao G-Q, Liu L, et al. Long non-coding RNA LINC00968 attenuates drug resistance of breast cancer cells through inhibiting the Wnt2/ $\beta$-catenin signaling pathway by regulating WNT2. J Exp Clin Cancer Res. 2019;38(1):94.

36. Wan W, Hou Y, Wang K, Cheng Y, Pu X, Ye X. The LXR-623-induced long non-coding RNA LINC01125 suppresses the proliferation of breast cancer cells via PTEN/AKT/p53 signaling pathway. Cell Death Dis. 2019;10(3):248.

37. Tu Z, Schmöllerl J, Cuiffo BG, Karnoub AE. Microenvironmental regulation of long noncoding RNA LINC01133 promotes cancer stem cell-like phenotypic traits in triple-negative breast cancers. Stem Cells. 2019;37(10):1281-92.

38. Ai B, Kong X, Wang X, Zhang K, Yang X, Zhai J, et al. LINC01355 suppresses breast cancer growth through $\mathrm{FOXO3-mediated} \mathrm{transcriptional} \mathrm{repression}$ of CCND1. Cell Death Dis. 2019;10(7):502.

39. Luo L, Tang H, Ling L, Li N, Jia X, Zhang Z, et al. LINC01638 IncRNA activates MTDH-Twist1 signaling by preventing SPOP-mediated c-Myc degradation in triple-negative breast cancer. Oncogene. 2018;37(47):6166-79.

40. Wang B, Zheng J, Li R, Tian Y, Lin J, Liang Y, et al. Long noncoding RNA LINC02582 acts downstream of miR-200c to promote radioresistance through CHK1 in breast cancer cells. Cell Death Dis. 2019:10(10):764.

41. Jiang Z, Slater CM, Zhou Y, Devarajan K, Ruth KJ, Li Y, et al. LincIN, a novel NF90-binding long non-coding RNA, is overexpressed in advanced breast tumors and involved in metastasis. Breast Cancer Res. 2017;19(1):62.

42. Li J, Hao Y, Mao W, Xue X, Xu P, Liu L, et al. LincK contributes to breast tumorigenesis by promoting proliferation and epithelial-to-mesenchymal transition. J Hematol Oncol. 2019;12(1):19.

43. Liao X-H, Wang J-G, Li L-Y, Zhou D-M, Ren K-H, Jin Y-T, et al. Long intergenic non-coding RNA APOC1P1-3 inhibits apoptosis by decreasing atubulin acetylation in breast cancer. Cell Death Dis. 2016;7:e2236.

44. Peng W-X, Huang J-G, Yang L, Gong A-H, Mo Y-Y. Linc-RoR promotes MAPKJERK signaling and confers estrogen-independent growth of breast cancer. Mol Cancer. 2017;16(1):161.

45. Wang P-S, Chou C-H, Lin C-H, Yao Y-C, Cheng H-C, Li H-Y, et al. A novel long noncoding RNA linc-ZNF469-3 promotes lung metastasis through miR-574-5p-ZEB1 axis in triple negative breast cancer. Oncogene. 2018;37(34):4662-78.

46. de Silva HC, Lin MZ, Phillips L, Martin JL, Baxter RC. IGFBP-3 interacts with NONO and SFPQ in PARP-dependent DNA damage repair in triple-negative breast cancer. Cell Mol Life Sci. 2019;76(10):2015-30.

47. Li R-H, Chen M, Liu J, Shao C-C, Guo C-P, Wei X-L, et al. Long noncoding RNA ATB promotes the epithelial-mesenchymal transition by upregulating the miR-200c/Twist1 axe and predicts poor prognosis in breast cancer. Cell Death Dis. 2018;9(12):1171.

48. Wang S, Liang K, Hu Q, Li P, Song J, Yang Y, et al. JAK2-binding long noncoding RNA promotes breast cancer brain metastasis. J Clin Invest. 2017;127(12):4498-515.

49. Sun M, Gadad SS, Kim D-S, Kraus WL. Discovery, annotation, and functional analysis of long noncoding RNAs controlling cell-cycle gene expression and proliferation in breast cancer cells. Mol Cell. 2015;59(4):698-711.

50. Zhou M, Hou Y, Yang G, Zhang H, Tu G, Du Y, et al. LncRNA-Hh strengthen cancer stem cells generation in twist-positive breast cancer via activation of hedgehog signaling pathway. Stem Cells. 2016;34(1):55-66.

51. Das M, Renganathan A, Dighe SN, Bhaduri U, Shettar A, Mukherjee G, et al. DDX5/p68 associated IncRNA LOC284454 is differentially expressed in human cancers and modulates gene expression. RNA Biol. 2018;15(2): 214-30.

52. Li C, Wang S, Xing Z, Lin A, Liang K, Song J, et al. A ROR1-HER3-IncRNA signalling axis modulates the hippo-YAP pathway to regulate bone metastasis. Nat Cell Biol. 2017;19(2):106-19.

53. Fish L, Pencheva N, Goodarzi H, Tran H, Yoshida M, Tavazoie SF. Muscleblind-like 1 suppresses breast cancer metastatic colonization and stabilizes metastasis suppressor transcripts. Genes Dev. 2016;30(4):386-98.

54. Mondal T, Subhash S, Vaid R, Enroth S, Uday S, Reinius B, et al. MEG3 long noncoding RNA regulates the TGF- $\beta$ pathway genes through formation of RNA-DNA triplex structures. Nat Commun. 2015;6:7743.

55. Wang $\mathrm{S}, \mathrm{Ke} H$, Zhang H, Ma Y, Ao L, Zou L, et al. LncRNA MIR100HG promotes cell proliferation in triple-negative breast cancer through triplex formation with p27 loci. Cell Death Dis. 2018;9(8):805.

56. Zhang X, Schulz R, Edmunds S, Krüger E, Markert E, Gaedcke J, et al MicroRNA-101 suppresses tumor cell proliferation by acting as an endogenous proteasome inhibitor via targeting the proteasome assembly factor POMP. Mol Cell. 2015;59(2):243-57.

57. Liu B, Sun L, Liu Q, Gong C, Yao Y, Lv X, et al. A cytoplasmic NF-kB interacting long noncoding RNA blocks IKB phosphorylation and suppresses breast cancer metastasis. Cancer Cell. 2015;27(3):370-81.

58. Mao C, Wang X, Liu Y, Wang M, Yan B, Jiang Y, et al. A G3BP1-interacting IncRNA promotes ferroptosis and apoptosis in cancer via nuclear sequestration of p53. Cancer Res. 2018;78(13):3484-96.

59. Gong C, Qu S, Lv X-B, Liu B, Tan W, Nie Y, et al. BRMS1L suppresses breast cancer metastasis by inducing epigenetic silence of FZD10. Nat Commun. 2014;5:5406.

60. Liu X, Bi L, Wang Q, Wen M, Li C, Ren Y, et al. miR-1204 targets VDR to promotes epithelial-mesenchymal transition and metastasis in breast cancer. Oncogene. 2018;37(25):3426-39.

61. Fong MY, Zhou W, Liu L, Alontaga AY, Chandra M, Ashby J, et al. Breastcancer-secreted miR-122 reprograms glucose metabolism in premetastatic niche to promote metastasis. Nat Cell Biol. 2015;17(2):183-94.

62. Cai W-L, Huang W-D, Li B, Chen T-R, Li Z-X, Zhao C-L, et al. microRNA-124 inhibits bone metastasis of breast cancer by repressing interleukin-11. Mol Cancer. 2018;17(1):9.

63. Li G, Wu X, Qian W, Cai H, Sun X, Zhang W, et al. CCAR1 5' UTR as a natural miRancer of miR-1254 overrides tamoxifen resistance. Cell Res. 2016;26(6): 655-73

64. Xu Y, Ji K, Wu M, Hao B, Yao K-T, Xu Y. A miRNA-HERC4 pathway promotes breast tumorigenesis by inactivating tumor suppressor LATS1. Protein Cell. 2019;10(8):595-605.

65. Wei H, Cui R, Bahr J, Zanesi N, Luo Z, Meng W, et al. miR-130a deregulates PTEN and stimulates tumor growth. Cancer Res. 2017;77(22):6168-78.

66. Hanieh $\mathrm{H}$. Aryl hydrocarbon receptor-microRNA-212/132 axis in human breast cancer suppresses metastasis by targeting SOX4. Mol Cancer. 2015; 14:172.

67. Taipaleenmäki H, Browne G, Akech J, Zustin J, van Wijnen AJ, Stein JL, et al. Targeting of Runx2 by miR-135 and miR-203 impairs progression of breast cancer and metastatic bone disease. Cancer Res. 2015;75(7):1433-44.

68. Zhang W, Wu M, Chong Q-Y, Zhang M, Zhang X, Hu L, et al. Loss of estrogen-regulated MIR135A1 at 3p21.1 promotes tamoxifen resistance in breast cancer. Cancer Res. 2018;78(17):4915-28.

69. Bockhorn J, Prat A, Chang Y-F, Liu X, Huang S, Shang M, et al. Differentiation and loss of malignant character of spontaneous pulmonary metastases in patient-derived breast cancer models. Cancer Res. 2014;74(24):7406-17.

70. Pajic M, Froio D, Daly S, Doculara L, Millar E, Graham PH, et al. miR$139-5 p$ modulates radiotherapy resistance in breast cancer by 
repressing multiple gene networks of DNA repair and ROS defense. Cancer Res. 2018;78(2):501-15.

71. Tang X, Hou Y, Yang G, Wang X, Tang S, Du Y-E, et al. Stromal miR-200s contribute to breast cancer cell invasion through CAF activation and ECM remodeling. Cell Death Differ. 2016;23(1):132-45.

72. Isobe T, Hisamori S, Hogan DJ, Zabala M, Hendrickson DG, Dalerba P, et al. miR-142 regulates the tumorigenicity of human breast cancer stem cells through the canonical WNT signaling pathway. Elife. 2014;3:e01977.

73. Jia J, Shi Y, Chen L, Lai W, Yan B, Jiang Y, et al. Decrease in lymphoid specific helicase and 5-hydroxymethylcytosine is associated with metastasis and genome instability. Theranostics. 2017;7(16):3920-32.

74. Wang G, Gormley M, Qiao J, Zhao Q, Wang M, Di Sante G, et al. Cyclin D1mediated microRNA expression signature predicts breast cancer outcome. Theranostics. 2018;8(8):2251-63.

75. Orso F, Quirico L, Virga F, Penna E, Dettori D, Cimino D, et al. miR-214 and miR-148b targeting inhibits dissemination of melanoma and breast cancer. Cancer Res. 2016;76(17):5151-62.

76. Liu R, Shi P, Nie Z, Liang H, Zhou Z, Chen W, et al. Mifepristone suppresses basal triple-negative breast cancer stem cells by down-regulating KLF5 expression. Theranostics. 2016;6(4):533-44.

77. Bacci M, Giannoni E, Fearns A, Ribas R, Gao Q, Taddei ML, et al. miR-155 drives metabolic reprogramming of ER+ breast cancer cells following longterm estrogen deprivation and predicts clinical response to aromatase inhibitors. Cancer Res. 2016;76(6):1615-26.

78. Chin AR, Fong MY, Somlo G, Wu J, Swiderski P, Wu X, et al. Cross-kingdom inhibition of breast cancer growth by plant miR159. Cell Res. 2016;26(2): 217-28.

79. Tominaga N, Kosaka N, Ono M, Katsuda T, Yoshioka Y, Tamura K, et al. Brain metastatic cancer cells release microRNA-181c-containing extracellular vesicles capable of destructing blood-brain barrier. Nat Commun. 2015;6:6716.

80. Lu G, Li Y, Ma Y, Lu J, Chen Y, Jiang Q, et al. Long noncoding RNA LINC00511 contributes to breast cancer tumourigenesis and stemness by inducing the miR-185-3p/E2F1/Nanog axis. J Exp Clin Cancer Res. 2018;37(1):289.

81. Zhang N, Zhang H, Liu Y, Su P, Zhang J, Wang X, et al. SREBP1, targeted by miR-18a-5p, modulates epithelial-mesenchymal transition in breast cancer via forming a co-repressor complex with snail and HDAC1/2. Cell Death Differ. 2019;26(5):843-59.

82. Yu Y, Luo W, Yang Z-J, Chi J-R, Li Y-R, Ding Y, et al. miR-190 suppresses breast cancer metastasis by regulation of TGF- $\beta$-induced epithelialmesenchymal transition. Mol Cancer. 2018;17(1):70.

83. Shen M, Dong C, Ruan X, Yan W, Cao M, Pizzo D, et al. Chemotherapyinduced extracellular vesicle miRNAs promote breast cancer stemness by targeting ONECUT2. Cancer Res. 2019;79(14):3608-21.

84. Celià-Terrassa T, Liu DD, Choudhury A, Hang X, Wei Y, Zamalloa J, et al. Normal and cancerous mammary stem cells evade interferon-induced constraint through the miR-199a-LCOR axis. Nat Cell Biol. 2017;19(6):711-23.

85. Liu B, Du R, Zhou L, Xu J, Chen S, Chen J, et al. miR-200c/141 regulates breast cancer stem cell heterogeneity via targeting HIPK1/ $\beta$-catenin axis. Theranostics. 2018;8(21):5801-13.

86. Hong BS, Ryu HS, Kim N, Kim J, Lee E, Moon H, et al. Tumor suppressor miRNA204-5p regulates growth, metastasis, and immune microenvironment remodeling in breast cancer. Cancer Res. 2019;79(7):1520-34.

87. Samaeekia R, Adorno-Cruz V, Bockhorn J, Chang Y-F, Huang S, Prat A, et al. miR-206 inhibits stemness and metastasis of breast cancer by targeting MKL1/IL11 pathway. Clin Cancer Res. 2017;23(4):1091-103.

88. Si W, Shen J, Du C, Chen D, Gu X, Li C, et al. A miR-20a/MAPK1/C-Myc regulatory feedback loop regulates breast carcinogenesis and chemoresistance. Cell Death Differ. 2018;25(2):406-20.

89. Liu Y, Xu J, Choi HH, Han C, Fang Y, Li Y, et al. Targeting 17q23 amplicon to overcome the resistance to anti-HER2 therapy in HER2+ breast cancer. Nat Commun. 2018;9(1):4718

90. Li X-Y, Zhou L-Y, Luo H, Zhu Q, Zuo L, Liu G-Y, et al. The long noncoding RNA MIR210HG promotes tumor metastasis by acting as a ceRNA of miR1226-3p to regulate mucin-1c expression in invasive breast cancer. Aging (Albany NY). 2019;11(15):5646-65.

91. Ren W, Guan W, Zhang J, Wang F, Xu G. Pyridoxine 5'-phosphate oxidase is correlated with human breast invasive ductal carcinoma development. Aging (Albany NY). 2019;11(7):2151-76.

92. Han C, Li X, Fan Q, Liu G, Yin J. CCAT1 promotes triple-negative breast cancer progression by suppressing miR-218/ZFX signaling. Aging (Albany NY). 2019;11(14):4858-75.
93. Pradhan AK, Talukdar S, Bhoopathi P, Shen X-N, Emdad L, Das SK, et al. mda-7/IL-24 mediates cancer cell-specific death via regulation of miR-221 and the beclin-1 axis. Cancer Res. 2017;77(4):949-59.

94. Cui S, Liao X, Ye C, Yin X, Liu M, Hong Y, et al. ING5 suppresses breast cancer progression and is regulated by miR-24. Mol Cancer. 2017;16(1):89.

95. Rasheed SAK, Teo CR, Beillard EJ, Voorhoeve PM, Zhou W, Ghosh S, et al. MicroRNA-31 controls G protein alpha-13 (GNA13) expression and cell invasion in breast cancer cells. Mol Cancer. 2015;14:67.

96. Hannafon BN, Carpenter K, Berry WL, Janknecht R, Dooley WC, Ding W-Q. Exosome-mediated microRNA signaling from breast cancer cells is altered by the anti-angiogenesis agent docosahexaenoic acid (DHA). Mol Cancer. 2015;14:133.

97. Kang H, Kim C, Lee H, Rho JG, Seo J-W, Nam J-W, et al. Downregulation of microRNA-362-3p and microRNA-329 promotes tumor progression in human breast cancer. Cell Death Differ. 2016;23(3):484-95.

98. Zhang C, Zhang Y, Ding W, Lin Y, Huang Z, Luo Q. MiR-33a suppresses breast cancer cell proliferation and metastasis by targeting ADAM9 and ROS1. Protein Cell. 2015;6(12):881-9.

99. Kaverina N, Borovjagin AV, Kadagidze Z, Baryshnikov A, Baryshnikova M, Malin D, et al. Astrocytes promote progression of breast cancer metastases to the brain via a KISS1-mediated autophagy. Autophagy. 2017;13(11):1905-23.

100. Furuta S, Ren G, Mao J-H, Bissell MJ. Laminin signals initiate the reciprocal loop that informs breast-specific gene expression and homeostasis by activating NO, p53 and microRNAs. Elife. 2018;21:7.

101. Frank A-C, Ebersberger S, Fink AF, Lampe S, Weigert A, Schmid T, et al. Apoptotic tumor cell-derived microRNA-375 uses CD36 to alter the tumorassociated macrophage phenotype. Nat Commun. 2019;10(1):1135.

102. Rodriguez-Barrueco R, Nekritz EA, Bertucci F, Yu J, Sanchez-Garcia F, Zeleke TZ, et al. miR-424(322)/503 is a breast cancer tumor suppressor whose loss promotes resistance to chemotherapy. Genes Dev. 2017;31(6):553-66.

103. Zhao Z, Li L, Du P, Ma L, Zhang W, Zheng L, et al. Transcriptional downregulation of miR-4306 serves as a new therapeutic target for triple negative breast cancer. Theranostics. 2019;9(5):1401-16.

104. Ren L, Chen H, Song J, Chen X, Lin C, Zhang X, et al. MiR-454-3p-mediated Wnt/ $\beta$-catenin signaling antagonists suppression promotes breast cancer metastasis. Theranostics. 2019;9(2):449-65.

105. Floros KV, Lochmann TL, Hu B, Monterrubio C, Hughes MT, Wells JD, et al. Coamplification of miR-4728 protects HER2-amplified breast cancers from targeted therapy. Proc Natl Acad Sci U S A. 2018;115(11):E2594-603.

106. Liang Y, Song X, Li Y, Sang Y, Zhang N, Zhang H, et al. A novel long noncoding RNA-PRLB acts as a tumor promoter through regulating miR-47665p/SIRT1 axis in breast cancer. Cell Death Dis. 2018;9(5):563.

107. Ye F-G, Song C-G, Cao Z-G, Xia C, Chen D-N, Chen L, et al. Cytidine deaminase axis modulated by miR-484 differentially regulates cell proliferation and chemoresistance in breast cancer. Cancer Res. 2015;75(7):1504-15.

108. Pardo OE, Castellano L, Munro CE, Hu Y, Mauri F, Krell J, et al. miR-515-5p controls cancer cell migration through MARK4 regulation. EMBO Rep. 2016;17(4):570-84.

109. Li L, Liang Y, Kang L, Liu Y, Gao S, Chen S, et al. Transcriptional regulation of the warburg effect in cancer by SIX1. Cancer Cell. 2018;33(3):368-385.e7.

110. Zhan Y, Liang $X$, Li L, Wang B, Ding F, Li Y, et al. MicroRNA-548j functions as a metastasis promoter in human breast cancer by targeting Tensin1. Mol Oncol. 2016;10(6):838-49.

111. Zheng $A$, Song $X$, Zhang $L$, Zhao L, Mao X, Wei M, et al. Long non-coding RNA LUCAT1/miR-5582-3p/TCF7L2 axis regulates breast cancer stemness via Wnt/ß-catenin pathway. J Exp Clin Cancer Res. 2019;38(1):305.

112. El Helou R, Pinna G, Cabaud O, Wicinski J, Bhajun R, Guyon L, et al. miR-600 acts as a bimodal switch that regulates breast cancer stem cell fate through WNT signaling. Cell Rep. 2017;18(9):2256-68.

113. Jiang L, Yu L, Zhang $X$, Lei F, Wang L, Liu X, et al. miR-892b silencing activates NF-kB and promotes aggressiveness in breast cancer. Cancer Res. 2016;76(5):1101-11.

114. Wu M-Z, Cheng W-C, Chen S-F, Nieh S, O'Connor C, Liu C-L, et al. miR-25/93 mediates hypoxia-induced immunosuppression by repressing CGAS. Nat Cell Biol. 2017;19(10):1286-96.

115. Hashimoto K, Ochi H, Sunamura S, Kosaka N, Mabuchi Y, Fukuda T, et al. Cancer-secreted hsa-miR-940 induces an osteoblastic phenotype in the bone metastatic microenvironment via targeting ARHGAP1 and FAM134A. Proc Natl Acad Sci U S A. 2018;115(9):2204-9.

116. Bailey ST, Westerling T, Brown M. Loss of estrogen-regulated microRNA expression increases HER2 signaling and is prognostic of poor outcome in luminal breast cancer. Cancer Res. 2015;75(2):436-45. 
117. Pellecchia S, Sepe R, Federico A, Cuomo M, Credendino SC, Pisapia P, et al. The metallophosphoesterase-domain-containing protein 2 (MPPED2) gene acts as tumor suppressor in breast cancer. Cancers (Basel). 2019;11(6):797.

118. Zhang H, Zhang N, Liu Y, Su P, Liang Y, Li Y, et al. Epigenetic regulation of NAMPT by NAMPT-AS drives metastatic progression in triple-negative breast cancer. Cancer Res. 2019:79(13):3347-59.

119. Liu X, Xiao Z-D, Han L, Zhang J, Lee S-W, Wang W, et al. LncRNA NBR2 engages a metabolic checkpoint by regulating AMPK under energy stress. Nat Cell Biol. 2016;18(4):431-42.

120. Yeh C-C, Luo J-L, Nhut Phan N, Cheng Y-C, Chow L-P, Tsai M-H, et al. Different effects of long noncoding RNA NDRG1-OT1 fragments on NDRG1 transcription in breast cancer cells under hypoxia. RNA Biol. 2018;15(12): 1487-98.

121. Yao N, Fu Y, Chen L, Liu Z, He J, Zhu Y, et al. Long non-coding RNA NONHSAT101069 promotes epirubicin resistance, migration, and invasion of breast cancer cells through NONHSAT101069/miR-129-5p/Twist1 axis. Oncogene. 2019;38(47):7216-33.

122. Tan B-S, Yang M-C, Singh S, Chou Y-C, Chen H-Y, Wang M-Y, et al. LncRNA NORAD is repressed by the YAP pathway and suppresses lung and breast cancer metastasis by sequestering S100P. Oncogene. 2019;38(28):5612-26.

123. Jadaliha $M$, Gholamalamdari $O$, Tang W, Zhang Y, Petracovici A, Hao Q, et al. A natural antisense IncRNA controls breast cancer progression by promoting tumor suppressor gene mRNA stability. PLoS Genet. 2018;14(11):e1007802.

124. Balaratnam S, West N, Basu S. A piRNA utilizes HILI and HIWI2 mediated pathway to down-regulate ferritin heavy chain 1 mRNA in human somatic cells. Nucleic Acids Res. 2018;46(20):10635-48.

125. Tan L, Mai D, Zhang B, Jiang X, Zhang J, Bai R, et al. PIWl-interacting RNA36712 restrains breast cancer progression and chemoresistance by interaction with SEPW1 pseudogene SEPW1P RNA. Mol Cancer. 2019;18(1):9.

126. Abell NS, Mercado M, Cañeque T, Rodriguez R, Xhemalce B. Click quantitative mass spectrometry identifies PIWIL3 as a mechanistic target of RNA interference activator enoxacin in cancer cells. J Am Chem Soc. 2017; 139(4):1400-3.

127. Grelet S, Link LA, Howley B, Obellianne C, Palanisamy V, Gangaraju VK, et al. A regulated PNUTS mRNA to IncRNA splice switch mediates EMT and tumour progression. Nat Cell Biol. 2017;19(9):1105-15.

128. Gao X, Qin T, Mao J, Zhang J, Fan S, Lu Y, et al. PTENP1/miR-20a/PTEN axis contributes to breast cancer progression by regulating PTEN via PI3K/AKT pathway. J Exp Clin Cancer Res. 2019;38(1):256.

129. Tang J, Li Y, Sang Y, Yu B, Lv D, Zhang W, et al. LncRNA PVT1 regulates triple-negative breast cancer through KLF5/beta-catenin signaling. Oncogene. 2018;37(34):4723-34.

130. Miao H, Wang L, Zhan H, Dai J, Chang Y, Wu F, et al. A long noncoding RNA distributed in both nucleus and cytoplasm operates in the PYCARDregulated apoptosis by coordinating the epigenetic and translational regulation. PLoS Genet. 2019;15(5):e1008144

131. Sancisi V, Manzotti G, Gugnoni M, Rossi T, Gandolfi G, Gobbi G, et al. RUNX2 expression in thyroid and breast cancer requires the cooperation of three non-redundant enhancers under the control of BRD4 and c-JUN. Nucleic Acids Res. 2017:45(19):11249-67.

132. Jia $X$, Shi L, Wang $X$, Luo L, Ling L, Yin J, et al. KLF5 regulated IncRNA RP1 promotes the growth and metastasis of breast cancer via repressing p27kip1 translation. Cell Death Dis. 2019;10(5):373.

133. Chi J-R, Yu Z-H, Liu B-W, Zhang D, Ge J, Yu Y, et al. SNHG5 promotes breast cancer proliferation by sponging the miR-154-5p/PCNA axis. Mol Ther Nucleic Acids. 2019;17:138-49.

134. Shi Y, Li J, Liu Y, Ding J, Fan Y, Tian Y, et al. The long noncoding RNA SPRY4-IT1 increases the proliferation of human breast cancer cells by upregulating ZNF703 expression. Mol Cancer. 2015;14:51.

135. Luo M-L, Li J, Shen L, Chu J, Guo Q, Liang G, et al. The role of APAL/ ST8SIA6-AS1 InCRNA in PLK1 activation and mitotic catastrophe of tumor cells. J Natl Cancer Inst. 2019.

136. Fish L, Zhang S, Yu JX, Culbertson B, Zhou AY, Goga A, et al. Cancer cells exploit an orphan RNA to drive metastatic progression. Nat Med. 2018; 24(11):1743-51.

137. Dong H, Hu J, Zou K, Ye M, Chen Y, Wu C, et al. Activation of LncRNA TINCR by H3K27 acetylation promotes trastuzumab resistance and epithelialmesenchymal transition by targeting MicroRNA-125b in breast cancer. Mol Cancer. 2019;18(1):3.

138. Jin X, Xu X-E, Jiang Y-Z, Liu Y-R, Sun W, Guo Y-J, et al. The endogenous retrovirus-derived long noncoding RNA TROJAN promotes triple-negative breast cancer progression via ZMYND8 degradation. Sci Adv. 2019;5(3): eaat9820.

139. Tian J, Wang Y, Zhang X, Ren Q, Li R, Huang Y, et al. Calycosin inhibits the in vitro and in vivo growth of breast cancer cells through WDR7-7-GPR30 signaling. J Exp Clin Cancer Res. 2017;36(1):153.

140. Yin PT, Pongkulapa $\mathrm{T}$, Cho H-Y, Han J, Pasquale NJ, Rabie $\mathrm{H}$, et al. Overcoming chemoresistance in cancer via combined microRNA therapeutics with anticancer drugs using multifunctional magnetic coreshell nanoparticles. ACS Appl Mater Interfaces. 2018;10(32):26954-63.

141. Xing Z, Zhang Y, Liang K, Yan L, Xiang Y, Li C, et al. Expression of long noncoding RNA YIYA promotes glycolysis in breast cancer. Cancer Res. 2018;78(16):4524-32.

142. Lu Z, Jiao D, Qiao J, Yang S, Yan M, Cui S, et al. Restin suppressed epithelialmesenchymal transition and tumor metastasis in breast cancer cells through upregulating mir-200a/b expression via association with p73. Mol Cancer. 2015;14(1):102

143. Humphries B, Wang Z, Li Y, Jhan J-R, Jiang Y, Yang C. ARHGAP18 downregulation by miR-200b suppresses metastasis of triple-negative breast cancer by enhancing activation of RhoA. Cancer Res. 2017;77(15): 4051-64.

144. Chang C-C, Wu M-J, Yang J-Y, Camarillo IG, Chang C-J. Leptin-STAT3-G9a signaling promotes obesity-mediated breast cancer progression. Cancer Res. 2015;75(11):2375-86

145. Dang TT, Esparza MA, Maine EA, Westcott JM, Pearson GW. $\Delta$ Np63a promotes breast cancer cell motility through the selective activation of components of the epithelial-to-mesenchymal transition program. Cancer Res. 2015;75(18):3925-35.

146. Zhang P, Wang L, Rodriguez-Aguayo C, Yuan Y, Debeb BG, Chen D, et al. miR-205 acts as a tumour radiosensitizer by targeting ZEB1 and Ubc13. Nat Commun. 2014,5:5671

147. Le MTN, Hamar P, Guo C, Basar E, Perdigão-Henriques R, Balaj L, et al. miR200-containing extracellular vesicles promote breast cancer cell metastasis. J Clin Invest. 2014;124(12):5109-28.

148. Croset M, Pantano F, Kan CWS, Bonnelye E, Descotes F, Alix-Panabières C, et al. miRNA-30 family members inhibit breast cancer invasion, osteomimicry, and bone destruction by directly targeting multiple bone metastasis-associated genes. Cancer Res. 2018;78(18):5259-73.

149. di Gennaro A, Damiano V, Brisotto G, Armellin M, Perin T, Zucchetto A, et al. A p53/miR-30a/ZEB2 axis controls triple negative breast cancer aggressiveness. Cell Death Differ. 2018;25(12):2165-80.

150. Li Y, Kuscu C, Banach A, Zhang Q, Pulkoski-Gross A, Kim D, et al. miR-181a$5 p$ inhibits cancer cell migration and angiogenesis via downregulation of matrix metalloproteinase-14. Cancer Res. 2015;75(13):2674-85.

151. Liu K, Xie F, Gao A, Zhang R, Zhang L, Xiao Z, et al. SOX2 regulates multiple malignant processes of breast cancer development through the SOX2/miR181a-5p, miR-30e-5p/TUSC3 axis. Mol Cancer. 2017;16(1):62.

152. D'Ippolito E, Plantamura I, Bongiovanni L, Casalini P, Baroni S, Piovan C, et al. miR-9 and miR-200 regulate PDGFRß-mediated endothelial differentiation of tumor cells in triple-negative breast cancer. Cancer Res. 2016;76(18):5562-72.

153. Zhou Y, Meng $X$, Chen S, Li W, Li D, Singer R, et al. IMP1 regulates UCA1mediated cell invasion through facilitating UCA1 decay and decreasing the sponge effect of UCA1 for miR-122-5p. Breast Cancer Res. 2018;20(1):32.

154. Zhang J, Sui S, Wu H, Zhang J, Zhang X, Xu S, et al. The transcriptional landscape of IncRNAs reveals the oncogenic function of LINC00511 in ERnegative breast cancer. Cell Death Dis. 2019;10(8):599.

155. Ren Y, Wang Y-F, Zhang J, Wang Q-X, Han L, Mei M, et al. Targeted design and identification of AC1NOD4Q to block activity of HOTAIR by abrogating the scaffold interaction with EZH2. Clin Epigenetics. 2019;11(1):29.

156. Li Y, Wang Z, Shi H, Li H, Li L, Fang R, et al. HBXIP and LSD1 scaffolded by IncRNA hotair mediate transcriptional activation by c-Myc. Cancer Res. 2016;76(2):293-304.

157. Li M, Li X, Zhuang Y, Flemington EK, Lin Z, Shan B. Induction of a novel isoform of the InCRNA HOTAIR in Claudin-low breast cancer cells attached to extracellular matrix. Mol Oncol. 2017;11(12):1698-710.

158. Peng F, Li T-T, Wang K-L, Xiao G-Q, Wang J-H, Zhao H-D, et al. H19/let-7/ LIN28 reciprocal negative regulatory circuit promotes breast cancer stem cell maintenance. Cell Death Dis. 2017;8(1):e2569.

159. Peng F, Wang J-H, Fan W-J, Meng Y-T, Li M-M, Li T-T, et al. Glycolysis gatekeeper PDK1 reprograms breast cancer stem cells under hypoxia. Oncogene. 2018:37(8):1062-74.

160. Lin A, Li C, Xing Z, Hu Q, Liang K, Han L, et al. The LINK-A IncRNA activates normoxic HIF1a signalling in triple-negative breast cancer. Nat Cell Biol. 2016;18(2):213-24 
161. Wang J, Xie S, Yang J, Xiong H, Jia Y, Zhou Y, et al. The long noncoding RNA H19 promotes tamoxifen resistance in breast cancer via autophagy. J Hematol Oncol. 2019;12(1):81.

162. Lin A, Hu Q, Li C, Xing Z, Ma G, Wang C, et al. The LINK-A IncRNA interacts with Ptdlns $(3,4,5)$ P3 to hyperactivate AKT and confer resistance to AKT inhibitors. Nat Cell Biol. 2017;19(3):238-51.

163. Ingle JN, Xie F, Ellis MJ, Goss PE, Shepherd LE, Chapman J-AW, et al. Genetic polymorphisms in the long noncoding RNA MIR2052HG offer a pharmacogenomic basis for the response of breast cancer patients to aromatase inhibitor therapy. Cancer Res. 2016;76(23):7012-23.

164. Cairns J, Ingle JN, Kalari KR, Shepherd LE, Kubo M, Goetz MP, et al. The IncRNA MIR2052HG regulates ERa levels and aromatase inhibitor resistance through LMTK3 by recruiting EGR1. Breast Cancer Res. 2019;21(1):47.

165. Chen H, Pan H, Qian Y, Zhou W, Liu X. MiR-25-3p promotes the proliferation of triple negative breast cancer by targeting BTG2. Mol Cancer. 2018;17(1):4.

166. Singh R, Pochampally R, Watabe K, Lu Z, Mo Y-Y. Exosome-mediated transfer of miR-10b promotes cell invasion in breast cancer. Mol Cancer. 2014;13:256

167. Bahena-Ocampo I, Espinosa M, Ceballos-Cancino G, Lizarraga F, CamposArroyo D, Schwarz A, et al. miR-10b expression in breast cancer stem cells supports self-renewal through negative PTEN regulation and sustained AKT activation. EMBO Rep. 2016;17(5):648-58.

168. Yoo B, Kavishwar A, Ross A, Wang P, Tabassum DP, Polyak $K$, et al. Combining miR-10b-targeted nanotherapy with low-dose doxorubicin elicits durable regressions of metastatic breast cancer. Cancer Res. 2015; 75(20):4407-15.

169. Kim J, Siverly AN, Chen D, Wang M, Yuan Y, Wang Y, et al. Ablation of miR-10b suppresses oncogene-induced mammary tumorigenesis and metastasis and reactivates tumor-suppressive pathways. Cancer Res. 2016;76(21):6424-35.

170. Tomita S, Abdalla MOA, Fujiwara S, Matsumori H, Maehara K, Ohkawa Y, et al. A cluster of noncoding RNAs activates the ESR1 locus during breast cancer adaptation. Nat Commun. 2015;6:6966.

171. Abdalla MOA, Yamamoto T, Maehara K, Nogami J, Ohkawa Y, Miura H, et al. The Eleanor ncRNAs activate the topological domain of the ESR1 locus to balance against apoptosis. Nat Commun. 2019;10(1):3778.

172. Pruszko M, Milano E, Forcato M, Donzelli S, Ganci F, Di Agostino S, et al. The mutant p53-ID4 complex controls VEGFA isoforms by recruiting IncRNA MALAT1. EMBO Rep. 2017;18(8):1331-51.

173. Kim J, Piao H-L, Kim B-J, Yao F, Han Z, Wang Y, et al. Long noncoding RNA MALAT1 suppresses breast cancer metastasis. Nat Genet. 2018;50(12):1705-15.

174. Pakravan K, Babashah S, Sadeghizadeh M, Mowla SJ, MossahebiMohammadi M, Ataei F, et al. MicroRNA-100 shuttled by mesenchymal stem cell-derived exosomes suppresses in vitro angiogenesis through modulating the mTOR/HIF-1a/NEGF signaling axis in breast cancer cells. Cell Oncol (Dordr). 2017:40(5):457-70.

175. Deng L, Shang L, Bai S, Chen J, He X, Martin-Trevino R, et al. MicroRNA100 inhibits self-renewal of breast cancer stem-like cells and breast tumor development. Cancer Res. 2014;74(22):6648-60.

176. Li X, Xu Y, Ding Y, Li C, Zhao H, Wang J, et al. Posttranscriptional upregulation of HER3 by HER2 mRNA induces trastuzumab resistance in breast cancer. Mol Cancer. 2018;17(1):113.

177. Hsieh T-H, Hsu C-Y, Tsai C-F, Long C-Y, Wu C-H, Wu D-C, et al. HDAC inhibitors target HDAC5, upregulate microRNA-125a-5p, and induce apoptosis in breast cancer cells. Mol Ther. 2015;23(4):656-66.

178. Jin K, Park S, Teo WW, Korangath P, Cho SS, Yoshida T, et al. HOXB7 is an ERa cofactor in the activation of HER2 and multiple ER target genes leading to endocrine resistance. Cancer Discov. 2015;5(9):944-59.

179. Jiang C-F, Shi Z-M, Li D-M, Qian Y-C, Ren Y, Bai X-M, et al. Estrogen-induced miR-196a elevation promotes tumor growth and metastasis via targeting SPRED1 in breast cancer. Mol Cancer. 2018;17(1):83.

180. Yu J, Lei R, Zhuang X, Li X, Li G, Lev S, et al. MicroRNA-182 targets SMAD7 to potentiate TGF $\beta$-induced epithelial-mesenchymal transition and metastasis of cancer cells. Nat Commun. 2016;7:13884.

181. Velagapudi SP, Cameron MD, Haga CL, Rosenberg LH, Lafitte M, Duckett DR, et al. Design of a small molecule against an oncogenic noncoding RNA. Proc Natl Acad Sci U S A. 2016;113(21):5898-903.

182. Costales MG, Matsumoto Y, Velagapudi SP, Disney MD. Small molecule targeted recruitment of a nuclease to RNA. J Am Chem Soc. 2018;140(22): $6741-4$.
183. Gilam A, Conde J, Weissglas-Volkov D, Oliva N, Friedman E, Artzi N, et al Local microRNA delivery targets Palladin and prevents metastatic breast cancer. Nat Commun. 2016;7:12868.

184. Zhu J, Xiong G, Fu H, Evers BM, Zhou BP, Xu R. Chaperone Hsp47 drives malignant growth and invasion by modulating an ECM gene network. Cancer Res. 2015;75(8):1580-91.

185. Zhao H, Wilkie T, Deol Y, Sneh A, Ganju A, Basree M, et al. MiR-29b defines the pro-/anti-proliferative effects of S100A7 in breast cancer. Mol Cancer. 2015;14:11.

186. Müller V, Oliveira-Ferrer L, Steinbach B, Pantel K, Schwarzenbach H. Interplay of IncRNA H19/miR-675 and IncRNA NEAT1/miR-204 in breast cancer. Mol Oncol. 2019;13(5):1137-49.

187. Choudhry H, Albukhari A, Morotti M, Haider S, Moralli D, Smythies J, et al. Tumor hypoxia induces nuclear paraspeckle formation through HIF-2a dependent transcriptional activation of NEAT1 leading to cancer cell survival. Oncogene. 2015;34(34):4482-90.

188. Li W, Zhang Z, Liu X, Cheng $X$, Zhang $Y$, Han X, et al. The FOXN3-NEAT1SIN3A repressor complex promotes progression of hormonally responsive breast cancer. J Clin Invest. 2017;127(9):3421-40.

189. Takahashi R, Miyazaki H, Takeshita F, Yamamoto Y, Minoura K, Ono M, et al. Loss of microRNA-27b contributes to breast cancer stem cell generation by activating ENPP1. Nat Commun. 2015;6:7318.

190. Eastlack SC, Dong S, Ivan C, Alahari SK. Suppression of PDHX by microRNA27b deregulates cell metabolism and promotes growth in breast cancer. Mol Cancer. 2018;17(1):100

191. Bacci M, Lorito N, Ippolito L, Ramazzotti M, Luti S, Romagnoli S, et al. Reprogramming of amino acid transporters to support aspartate and glutamate dependency sustains endocrine resistance in breast cancer. Cell Rep. 2019;28(1):104-118.e8.

192. Xing Z, Lin A, Li C, Liang K, Wang S, Liu Y, et al. IncRNA directs cooperative epigenetic regulation downstream of chemokine signals. Cell. 2014;159(5): $1110-25$.

193. Zheng X, Han H, Liu G-P, Ma Y-X, Pan R-L, Sang L-J, et al. LncRNA wires up Hippo and Hedgehog signaling to reprogramme glucose metabolism. EMBO J. 2017:36(22):3325-35.

194. Adams BD, Wali VB, Cheng CJ, Inukai S, Booth CJ, Agarwal S, et al. MiR-34a silences C-SRC to attenuate tumor growth in triple-negative breast cancer. Cancer Res. 2016;76(4):927-39.

195. Ito $Y$, Inoue A, Seers T, Hato $Y$, Igarashi A, Toyama T, et al. Identification of targets of tumor suppressor microRNA-34a using a reporter library system. Proc Natl Acad Sci U S A. 2017;114(15):3927-32.

196. Weng Y-S, Tseng H-Y, Chen Y-A, Shen P-C, Al Haq AT, Chen L-M, et al. MCT1/miR-34a/IL-6/IL-6R signaling axis promotes EMT progression, cancer stemness and M2 macrophage polarization in triple-negative breast cancer. Mol Cancer. 2019;18(1):42.

197. Park EY, Chang E, Lee EJ, Lee H-W, Kang H-G, Chun K-H, et al. Targeting of miR34a-NOTCH1 axis reduced breast cancer stemness and chemoresistance. Cancer Res. 2014;74(24):7573-82.

198. Wang B, Li D, Kovalchuk I, Apel IJ, Chinnaiyan AM, Wóycicki RK, et al. MiR34a directly targets tRNAiMet precursors and affects cellular proliferation, cell cycle, and apoptosis. Proc Natl Acad Sci U S A. 2018;115(28):7392-7.

199. Bayraktar R, Ivan C, Bayraktar E, Kanlikilicer P, Kabil NN, Kahraman N, et al. Dual suppressive effect of miR-34a on the FOXM1/eEF2-kinase axis regulates triple-negative breast cancer growth and invasion. Clin Cancer Res. 2018; 24(17):4225-41.

200. Liu R, Liu C, Chen D, Yang W-H, Liu X, Liu C-G, et al. FOXP3 controls an miR146/NF-KB negative feedback loop that inhibits apoptosis in breast cancer cells. Cancer Res. 2015;75(8):1703-13.

201. Khawaled S, Suh SS, Abdeen SK, Monin J, Distefano R, Nigita G, et al. WWOX inhibits metastasis of triple-negative breast cancer cells via modulation of miRNAs. Cancer Res. 2019;79(8):1784-98.

\section{Publisher's Note}

Springer Nature remains neutral with regard to jurisdictional claims in published maps and institutional affiliations. 